\title{
Mitigation of Channel Shoaling at a Sheltered Inlet Subject to Flood Gate Operations
}

\author{
Laura Lemke *(i), Matthew S. Janssen $(1)$ and Jon K. Miller(D) \\ Coastal Engineering Research Group, Davidson Laboratory, Stevens Institute of Technology, Hoboken, NJ 07030, \\ USA; mjanssen@stevens.edu (M.S.J.); jmiller@stevens.edu (J.K.M.) \\ * Correspondence: llemke@stevens.edu
}

Received: 30 September 2020; Accepted: 29 October 2020; Published: 31 October 2020

\begin{abstract}
A comprehensive case study of Keansburg Inlet (New Jersey, USA) is presented with the objective of evaluating inlet management alternatives and assessing the influence of an operational flood gate on channel shoaling. The goal of the research is determining the most effective strategy for minimizing the frequency of maintenance dredging. This study compares the effectiveness of (1) traditional structural solutions; (2) modified dredging templates; and (3) assesses the influence of the flood gate operations during conditions representative of a typical year. Alternative analysis is completed using a coupled hydrodynamic-wave model (Delft3D-Flexible Mesh (FM)) with Real Time Control to simulate morphological changes. The model was calibrated and evaluated using collected field data. Water levels are reproduced within $6 \%$ of the spring tide range with lag times less than $20 \mathrm{~min}$. The model results and observations suggest sediment transport is dominated by wave action with pronounced variations in dominant wave direction. The results indicate that changes to the operational dredging, or what the authors have termed broadly as "adaptive dredging techniques", appear to deliver the most promising improvement. Model results suggest that the current operational procedures of the flood gate do not significantly alter the channel infilling rates and patterns during typical (i.e., non-extreme event) conditions.
\end{abstract}

Keywords: Delft3D model; maintenance dredging; Raritan Bay; tide/storm gate; small-craft harbor; shoaling; inlet morphology

\section{Introduction}

Inlets are hydraulic connections between open bodies of water and comparatively protected waters, providing numerous benefits (e.g., navigation, water quality). Historically, inlets have been broadly characterized as either primary or secondary inlets based on their formation [1] with the morphology of the inlet determined by the combined influence of tidal currents and waves. Correspondingly, the inlets are characterized as either wave or tidally dominated [2,3]. In general, inlets are naturally maintained through the scouring of tidal currents counteracting the longshore sediment transport; the concept of scour velocity, weakly correlated to sediment diameter, was first introduced in the middle of the 20th century [4,5]. Shoaling increases frictional losses and can reduce tidal velocities, eventually resulting in closure of the inlet [6,7]. With high ecologic and socio-economic values, natural inlets are often maintained through anthropogenic activities, including maintenance dredging and the construction of jetties or breakwaters. Historically, the prediction of inlet stability has been completed through empirical relationships developed via regression analysis [8-10] or through analytic solutions with required simplifications [11]. It is notable that historical work has typically been focused on either relatively large, primary inlets (e.g., [8,9]) or focused in the immediate area of the inlet throat (e.g., [11]).

While these simplified methods are convenient and provide some insight to the processes governing inlet stability, quantitative comparison of proposed anthropogenic activities (e.g., construction of erosion 
control structures or dredging operations) using these approaches is often not possible. Therefore, process-based models are often used to investigate both the processes driving sedimentation [12-14] and the potential impact of structural and non-structural inlet management alternatives [15-19]. Often, these studies have focused on larger open coast inlets. Other studies of small wave-dominated inlets have focused on the mechanisms of intermittent closure $[6,20,21]$ and the influence past mitigation strategies have had on the area [22].

Maintaining navigability includes maintenance of both the inlet throat and channel that extends seaward and landward of it [23]. Inlets in sheltered bays and along coasts with shallow gentle offshore slopes may have sediment bypassing occurring offshore of the inlet entrance, impeding the main channel and affecting navigation. Wave energy offshore of the inlet can easily mobilize sediments where depths are still shallow and generate significant longshore sediment transport. As currents dissipate once offshore of the inlet mouth, the currents may not be adequate to prevent sediment from being deposited. In these cases, the inlet width and depth cannot be optimized to eliminate the infilling of the channel offshore of the inlet [24]. The flushing capacity of tidal currents is often related to the tidal prism; assuming the conservation of mass, increases in the tidal prism will result in an increase in the magnitude of tidal currents. Empirical solutions have been developed by $[9,25]$ and [8] to estimate the minimum inlet cross section in relationship to the tidal prism; [26] developed relationships between tidal prism and littoral drift to predict the primary method of sand bypassing. It is worth noting that the smallest inlets explored in the aforementioned studies exhibited a tidal prism of the order of $10^{6} \mathrm{~m}^{3}$; the subject of this study is an order of magnitude smaller, at $10^{5} \mathrm{~m}^{3}$.

In further recognition of the increased social and economic importance of inlets, the surrounding areas typically exhibit high densities of residential and commercial structures. In an effort to decrease the vulnerability of the areas surrounding inlets in extreme events, flood control structures are occasionally used. Flood gates or storm gates are a common example. Structures that modify an inlet's cross-sectional area have the potential to influence its hydrodynamics and observed sedimentation patterns. These include both training structures (e.g., jetties), which act to redirect and constrain flow, as well as flood gates which may impede flow and decrease flushing capacity. Flood gates are physical barriers constructed across an inlet to prevent water from entering the back bay. While typically open during normal conditions, they may be closed during surge events to prevent back bay flooding. The construction of large storm surge barriers have been found to reduce the tidal range, tidal prism, and tidally driven flows [27,28]. Shallower channels offshore of the structure have been observed due to reduced scour. The existing literature focuses on these large barriers; the influence of smaller gates is less well documented. Additionally, the influence of intermittent closure on sedimentation patterns offshore represents a knowledge gap. With the increased occurrence of nuisance flooding expected to increase with climate change (e.g., [29,30]), understanding the influence of the intermittent and short duration closures becomes more important as the frequency and duration of flood gate closures increase.

This work aims to be an incremental step in assessing the potential management solutions for smaller secondary inlets such as Keansburg Inlet. While the details of the field data collection and numerical modeling are site specific, it is expected that the general methodology and conclusions may extend to other inlets servicing small craft harbors with comparatively small tidal prisms. Sites exhibiting these characteristics are underrepresented in the existing literature. The work presented herein has a distinct focus on the performance during typical (i.e., non-extreme) environmental forcing. The academic goals of the research can be summarized as follows:

1. Identify, quantify and recreate the dominate sediment pathways of a secondary inlet with a relatively small tidal prism under typical annual conditions;

2. Recreate historical sedimentation patterns and volumes through the use of a computationally efficient numerical model;

3. Assess the impact, relative importance and necessity to model the flood control structure (flood gate) during typical annual conditions; 
4. Compare the effectiveness of several structural and non-structure (adaptive dredging technique) sediment management options in a computationally efficient manner.

\section{Study Area}

\subsection{Site Description}

Keansburg Inlet is a secondary inlet connecting small-craft marinas located on Waackaack Creek and Thornes Creek to the Raritan Bay (Figure 1). The inlet predominantly serves recreation vessel traffic through a maintained channel. The channel has a charted depth of $-2.3 \mathrm{~m}$ relative to the North American Vertical Datum (NAVD) ( $-5 \mathrm{ft}$ relative to mean lower low water [MLLW]) and is maintained by the New Jersey Department of Transportation (NJDOT). The Bayshore Floodgate Facility, located at the junction of the two creeks, was constructed in 1973 as part of the U.S. Army Corps of Engineers' Beach Control and Hurricane Protection Project and consists of a flood gate and pump station. This facility is operated and maintained by the New Jersey Department of Environmental Protection (NJDEP) on a 24-h basis [31].
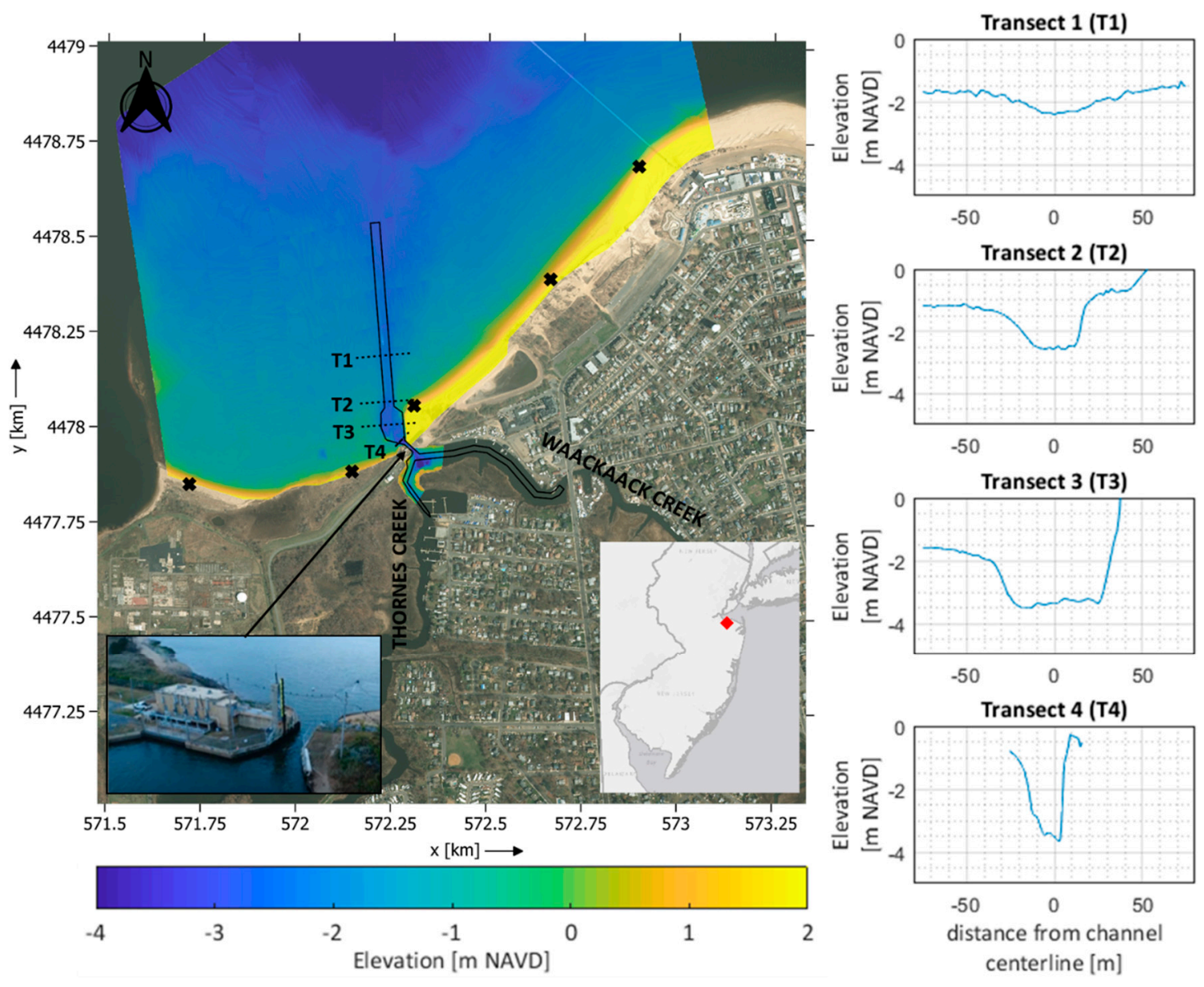

Figure 1. Site location map-Keansburg, New Jersey. Dredge template maintained by the New Jersey Department of Transportation (NJDOT), denoted by the black solid line. Bathymetry reflects that of March 2018. Transects (T1-T4) denoted in plan view (left) by black dashed lines with corresponding elevation profiles shown on right. Approximate sediment sample locations depicted as black X markers. At each location, three or more samples at varying elevations were collected, as described in Section 2.3. 


\subsection{Meteorologic and Hydraulic Characteristics}

Keansburg experiences semi-diurnal tides with a Great Diurnal Range of $1.66 \mathrm{~m}$ and mean range of $1.5 \mathrm{~m}$ (mean higher high water [MHHW] 0.77 m NAVD; MLLW -0.89 m NAVD). Consequently, the site can be classified as micro-tidal; tidal driven currents in microtidal shorelines are not expected to govern shoreline morphology [32]. The spring and neap tidal prism have been estimated to be $3.8 \times 10^{5} \mathrm{~m}^{3}$ and $3.4 \times 10^{5} \mathrm{~m}^{3}$, respectively.

The closest National Oceanic and Atmospheric Administration (NOAA) site with at least 15 years of wind records is located northeast of the project near the entrance to Raritan Bay at Sandy Hook, NJ (NOAA 8531680). The wind climate exhibits prominent seasonal trends, with winds coming primarily out of the west-northwest and out of the south-southeasterly quadrants. Winds are predominantly of interest for the associated locally generated wind waves. Consequently, based on the site geography, wind directions from west to east-northeast are of primary interest. Western winds are most often associated with the winter months; however, the northeastern winds are associated with the passage of weather systems and can occur at any point during the year. Average wind speeds are around $5 \mathrm{~m} / \mathrm{s}$ and maximums are $24 \mathrm{~m} / \mathrm{s}$, respectively. In general, the strongest winds of the year tend to come out of the west to northwest.

Wind roses for each season are provided in Figure 2 based on winds reported every six minutes between 2003 and 2018. It should be noted that the speeds provided have been adjusted assuming a logarithmic profile from the instrument height of $11.3 \mathrm{~m}$ to a standard $10 \mathrm{~m}$ height [33].

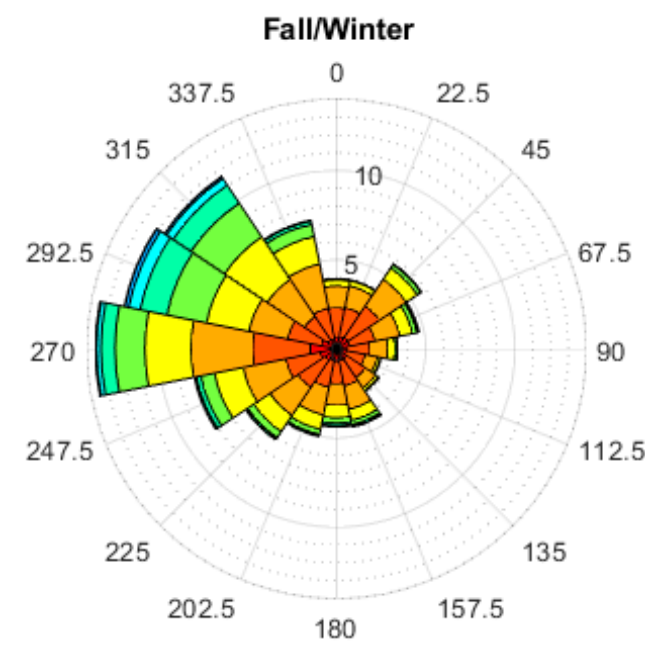

(a)

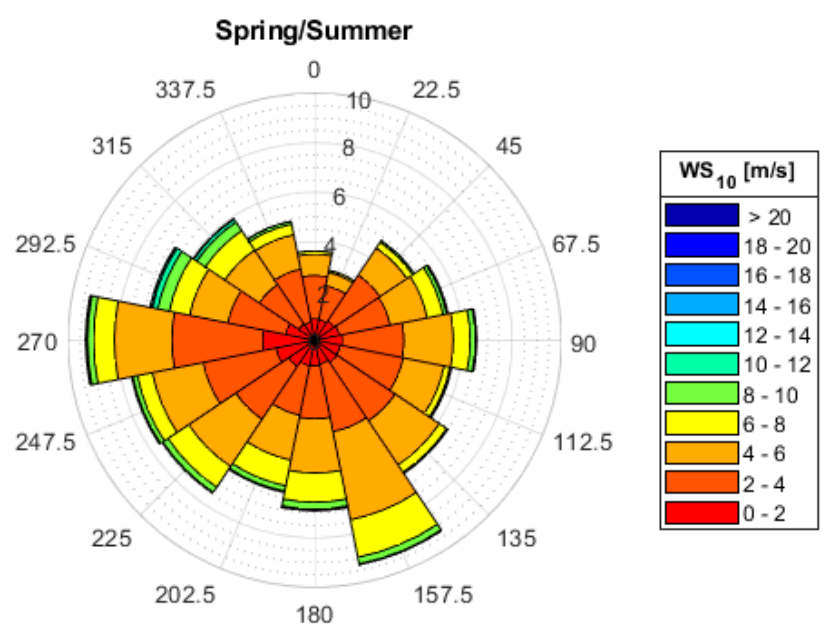

(b)

Figure 2. Seasonal wind roses for winter (a) and summer (b) at Sandy Hook (NOAA 8531680).

Waves at the project site are predominantly driven by local winds within Raritan Bay. However, the influence of the offshore swell propagating to the site was also considered. A sensitivity analysis using a standalone SWAN (Simulating WAves Nearshore) model found that offshore swell is largely dissipated before reaching the site (Table 1). For this test, a full range of wave heights, periods, and directions was considered to capture the conditions observed at the entrance to the Raritan Bay over the past forty years. Significant wave heights at the site due to offshore waves are less than $9 \mathrm{~cm} 99 \%$ of the time. Offshore swell events reach significant wave heights of $1.25 \mathrm{~m}$ offshore would produce wave heights on the order of $16 \mathrm{~cm}$ at the site. This height represents less than $20 \%$ of the expected locally generated wind waves of a comparable annual occurrence. 
Table 1. Sensitivity of local wave heights $\left(\mathrm{Hs}_{\mathrm{avg}}\right)$ to those at open boundary $\left(\mathrm{Hs}_{0}\right)$.

\begin{tabular}{cccc}
\hline $\mathbf{H s}_{\mathbf{0}}(\mathbf{m})$ & Frequency (\%) & $\mathbf{H s}_{\text {avg }}(\mathbf{m})$ & \% Reduction \\
\hline 0.25 & $87.0 \%$ & 0.04 & $86 \%$ \\
0.75 & $12.2 \%$ & 0.09 & $88 \%$ \\
1.25 & $0.7 \%$ & 0.16 & $87 \%$ \\
1.75 & $0.0 \%$ & 0.22 & $87 \%$ \\
\hline
\end{tabular}

It is expected that swell will have a limited impact on morphological changes at the site. This was confirmed through two sets of analyses. First, the limited impact of swell on net transport rates was explored and is discussed in Section 2.5, below. Second, typical and storm conditions using northeast sector winds (described in Section 3.3) were simulated with corresponding swell, forced at the open boundary $\left(\mathrm{H}_{\mathrm{s} 0}\right.$ of $0.5 \mathrm{~m}$ and 1.0 respectively), in a "do nothing" scenario. These results have been compared to those simulated without swell. It is found there are insignificant differences between the two results. Consequently, offshore swell influence was neglected.

\subsection{Sediment Characteristics}

Bottom sediment in the Raritan Bay is primarily sand. Silty sand can be found along the Raritan Bay channel and silt is prevalent to the north and west of the project site, nearing the Raritan River entrance [34]. The sediment at the site is dominated by sediment aptly named the "Keansburg Sands" [35]. Sediment diameters based on cores range from 0.05 to $0.35 \mathrm{~mm}$ [36]. As this study focuses on the relatively short-term movement of sands in the vicinity of the project site, the finer material will not be considered. Sediment size data is typically sparse for most New Jersey bayshore beaches. Work by [37] compiled sediment data for beaches in New Jersey that corresponded to NJ Beach Profile Network (NJBPN) locations. Data from the two most proximate NJBPN sites (ID \#185, \#286) to Keansburg Inlet are presented in Table 2.

Table 2. Sediment size data in the vicinity of Keansburg Inlet dimensional values in mm [37].

\begin{tabular}{cccccccc}
\hline Site ID \# & Location & Mean $(\mathbf{m m})$ & Mode $(\mathbf{m m})$ & Median $(\mathbf{m m})$ & Std. Dev. $(\mathbf{m m})$ & Skewness & Kurtosis \\
\hline 185 & Spy House Museum & 0.301 & 0.297 & 0.31 & 0.42 & 0.17 & 1.41 \\
286 & Front St. Union Beach & 0.328 & 0.297 & 0.337 & 0.44 & 0.18 & 1.08 \\
\hline
\end{tabular}

Additionally, seventeen sediment samples were obtained from Keansburg for grain size analysis. Samples were obtained at five locations and typically three cross-shore positions at each location. The cross-shore positions corresponded to within the swash zone (approximately mean low water [MLW]), mid beach (approximately mean high water [MHW]) and the dry beach (berm). A total of six samples were obtained from the beach west of Keansburg Inlet and eleven samples were obtained from the beach east of Keansburg Inlet including one sample extracted from exposed sediment at low tide on the channel side of the existing jetty (Figure 1). Sediment samples were analyzed using a sieve analysis consistent with specifications ASTM D421 and ASTM D422. Collected samples suggest a median $\left(\mathrm{d}_{50}\right)$ sediment diameter of $0.35 \mathrm{~mm}$ is appropriate.

\subsection{Historical Dredging Records}

Historical surveys performed by NJDOT from 2013 to 2016 are presented in Figure 3. A review of these records suggests net annual infill volumes within the limits of the channel are of the order of $1800 \mathrm{~m}^{3}$ per year. It is estimated that approximately half of that volume is typically concentrated in the immediate vicinity of the inlet throat and jetty (Figure $3 b$ ). It should be noted the estimates are made using the available pre- and post-dredge surveys. The limits of the surveys were not always consistent. However, as they were limited to the areas experiencing shoaling which were subsequently dredged, they are thought to capture the majority of the volume changes. In 2017, $3600 \mathrm{~m}^{3}$ of material was removed from the channel limits [38]. Annualizing this volume from the previous dredging project 
(2014) indicates the average annual dredge volumes of $1200 \mathrm{~m}^{3}$. A review of historical documents indicates that NJDOT is permitted to remove up to $4500 \mathrm{~m}^{3}$ of material per year [39].

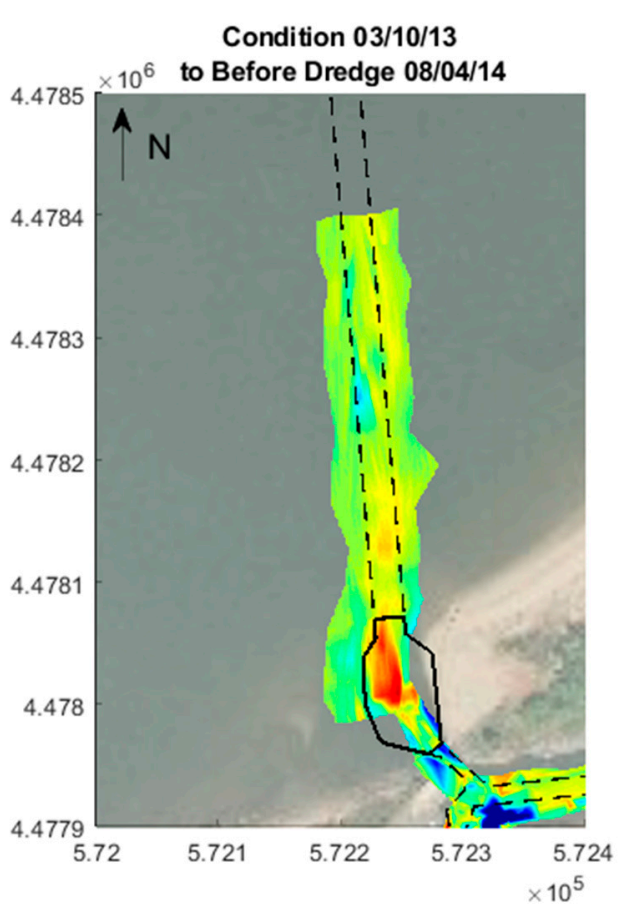

(a)

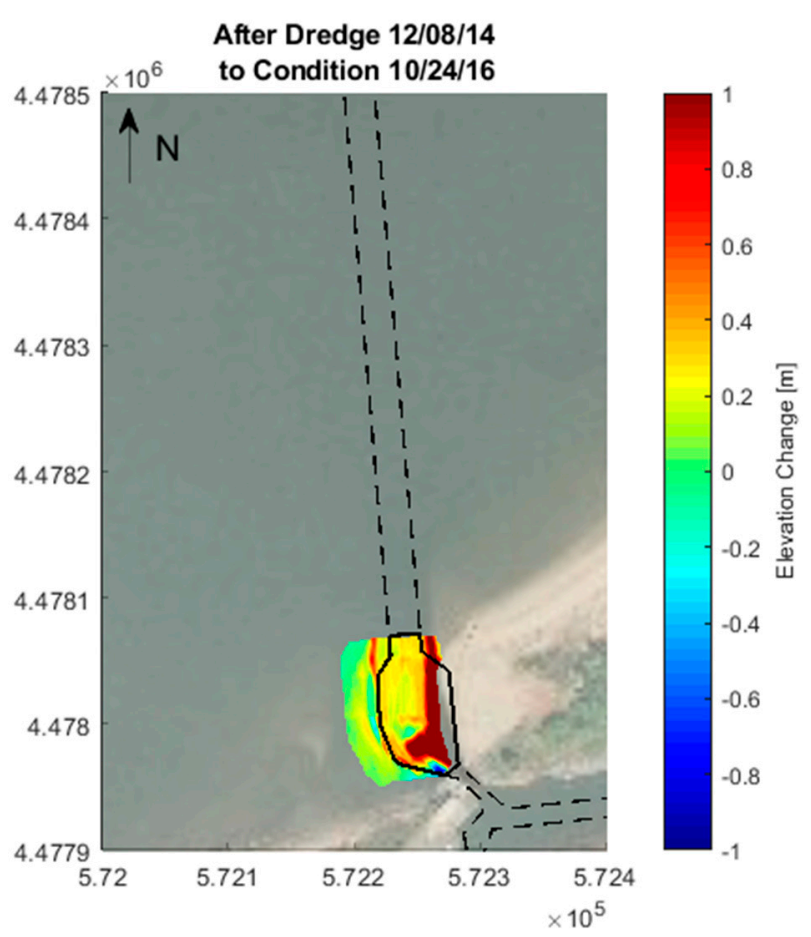

(b)

Figure 3. Elevation difference plots for two surveys within (a) design template footprint represented as a black dotted line and (b) partial dredging inlet throat smaller area for volume calculations as black solid line.

\subsection{Sediment Pathways and Aeolian Transport}

Field observations and measurements identified sediment deposition within the channel was likely due to three factors: wind-blown sediment leaking over the top of the existing East Jetty, alongshore transport during storm conditions, and movement of sediment related to flood gate operations (including operation of the pumps). Windblown transport contributions were estimated based on the given wind climate using empirical formulas developed by Hsu $[40,41]$ for aeolian sediment transport and presented within the Coastal Engineering Manual [42]. Volumes were estimated at approximately $450 \mathrm{~m}^{3} / \mathrm{y}\left( \pm 100 \mathrm{~m}^{3} / \mathrm{y}\right)$. This represents about $25 \%$ of the annual infilling volumes. The remaining volume is assumed to be the result of the other two factors.

It is expected that calibrated numerical models will provide more accurate representations of wave-induced sediment transport and the influence of flood gate operations than empirical formulas. The site includes a number of factors likely to influence these rates including local sheltering of waves by nearby structures, tidally induced flows, and complex bathymetry. However, the calculation of longshore sediment transport by empirical formulas is useful in estimating the relative importance of local and swell waves in gross transport rates and net direction. Using the commonly referred to "CERC formula" [42] the net transport rate is $3 \times 10^{4} \mathrm{~m}^{3} / \mathrm{y}$ to the east $\left(1 \times 10^{4} \mathrm{~m}^{3} / \mathrm{y}\right.$ to the west; $4 \times 10^{4} \mathrm{~m}^{3} / y$ to the east) due to locally driven waves. This is consistent with previous studies of the beach to the east of the inlet $[43,44]$. All transport by swell waves is towards the west $\left(1500 \mathrm{~m}^{3} / \mathrm{y}\right)$ and is just 3\% of the gross transport by wind waves, confirming the limited influence of swell waves on transport volumes. 


\subsection{Flood Gate Operational History and Sensitivity Analysis}

NJDEP operates a flood gate at Keansburg which restricts the flow into Waackaack Creek and Thornes Creek during periods of elevated water levels. Current operational guidelines call for the gate to close when the total water level exceeds approximately $0.8 \mathrm{~m}$ NAVD. The gate is also closed for testing, ice control, and maintenance. Gate closure reports were obtained from the NJDEP and analyzed. Figures 4 and 5 present summaries of the gate closures grouped by year (Figure 4 ) and by month (Figure 5).

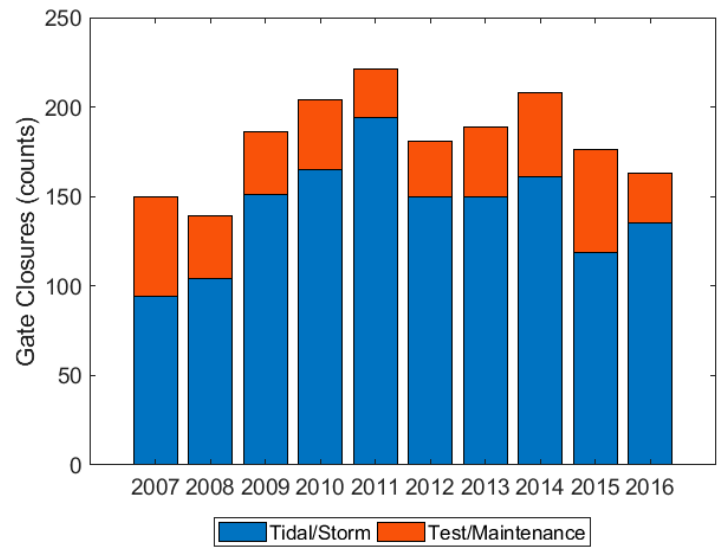

(a)

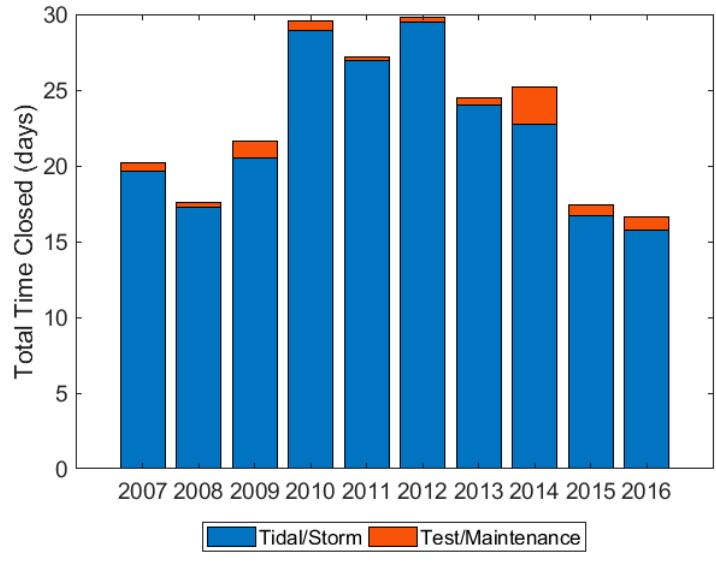

(b)

Figure 4. Number of gate closures (a) and total time closed (b) per year for 2007 to 2016.

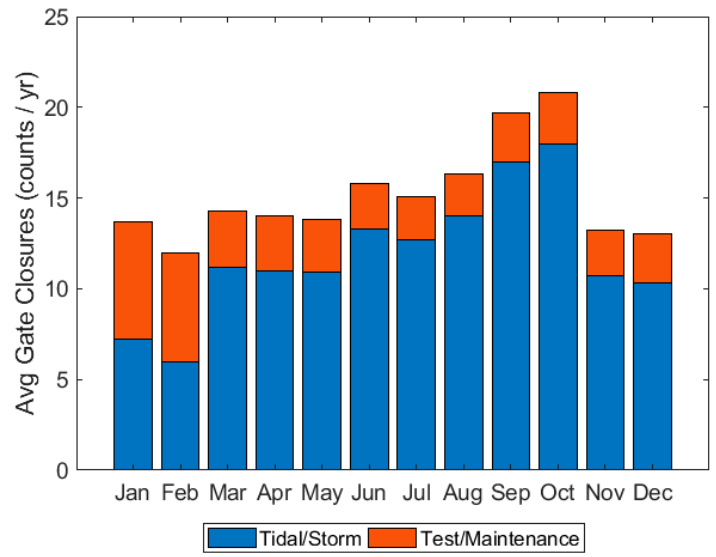

(a)

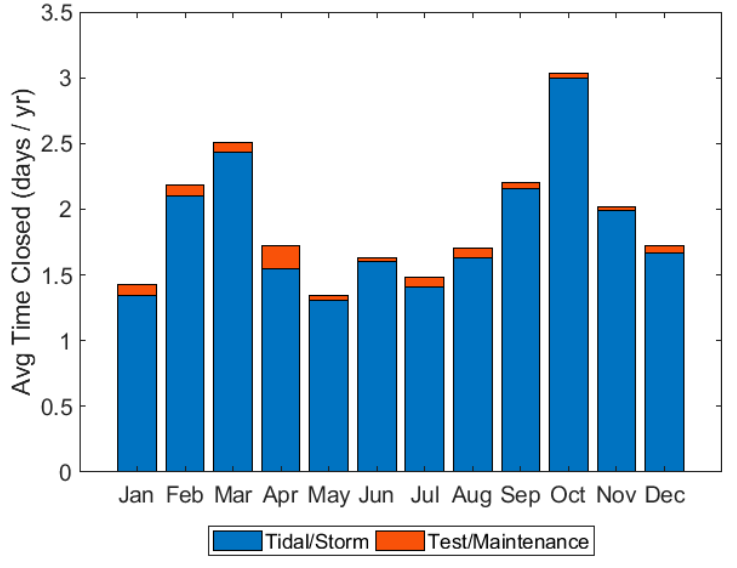

(b)

Figure 5. Average number of gate closures (a) and duration of closures per year (b) during each month based on gate closure data from 2007 to 2016.

Between 2007 and 2016 the flood gate was closed, on average, 180 times per year with 140 closures due to elevated water levels (Figure 4a). A typical gate closure occurs near high tide for a median of $3 \mathrm{~h}$. Several times a year, this becomes cyclical. Over the time scales ranging from several days to a week, the gate is closed for several hours every high tide. In the cases of major storms, it has been closed for upwards of five days continuously in the anticipation of elevated water levels. Between Hurricane Sandy (October 2012) and a nor'easter two weeks later, the gate was intermittently closed for a total of 12 days with the maximum length of a single closure at just over 5 days. In 2012, the flood gate was closed for a cumulative duration of nearly 30 days, much higher than the average of 17.5 (Figure $4 b$ ). When closed for other reasons like general testing or ice control the gate is typically closed and immediately reopened. This is most typical during the months of January and February (Figure 5a). 
However, for some maintenance work it has been closed for longer lengths of time, upwards of $34 \mathrm{~h}$. The closing of the gate takes about $12 \mathrm{~min}$.

\section{Methods}

A numerical model was utilized to further investigate the identified sediment pathways and evaluate the effectiveness of potential inlet management techniques in reducing sedimentation near the project site. An extensive field data collection in Spring of 2018 was successful in obtaining sufficient hydrodynamic, environmental, and morphologic data to enable the calibration and evaluation of a numerical model. First, the coupled hydrodynamic-wave model was calibrated and evaluated, followed then by calibration of the morphology component. This model was then adopted to evaluate the effectiveness of the various techniques (model application).

\subsection{Model Configuration}

This study utilized the modeling package Delft3D-Flexible Mesh (FM) [45], which has been routinely used to simulate the hydrodynamics and morphodynamics of complex inlet systems $[12,13,16,17]$. A depth-averaged $(2 \mathrm{DH})$ hydrodynamic module was coupled (two-way) with a wave module, based on SWAN [46,47], and a sediment transport module. The model covers Raritan Bay from its entrance at the Atlantic Ocean west towards the junction of the Raritan River and Arthur Kill (Figure 6). Depth information within the vicinity of the project site was interpolated from topographic and bathymetric data collected at the beginning of the Spring 2018 field collection using methods consistent with that of previous field studies [48,49]. Bathymetry was collected using a single-beam Odom sounder corrected for tides; the Dynamic Underwater Coastal Kinematic Surveying (DUCKS) system has an accuracy of 10-15 cm depending on wave conditions. Hydrographic survey transect spacing varied throughout the site, with higher densities ( $15 \mathrm{~m}$ spacing) in the area of interest around the inlet. Elevations above MLW were measured using an unmanned aerial system (UAS) with horizontal root mean square error (RMSE) of $2.2 \mathrm{~cm}$ and vertical RMSE of $2.5 \mathrm{~cm}$, respectively. In areas too shallow for the DUCKS, yet located subaqueous, traditional real-time kinematic global positioning system (RTK-GPS) survey methods were utilized. Areas of overlap between survey techniques were used whenever possible to ensure data continuity and quality. In areas with data overlap, data hierarchy used to create the elevation products utilized UAS point clouds first, followed by RTK-GPS walker data and then DUCKS measurements. Locations outside the immediate project site were interpolated from public sources [50].

Both Waackaack Creek and Thornes Creek (water bodies landward of Keansburg inlet) extend further inland than what was included in the scope of the model. While Thornes Creek (to the west) empties into Natco Lake via a man-made ditch, Waackaack Creek (to the east) connects to a large network of smaller channels. The particulars of the flow within these are not relevant to this study. Therefore, to facilitate computational efficiencies, these channels were parameterized as tidal basins (Figure $6 \mathrm{~b}$ ). The basins were sized to properly preserve the inlet's tidal prism and subsequent hydrodynamics.

The sheet pile located near the inlet entrance was modeled as an impermeable structure, blocking any movement of water, sand, and waves through it. The flood gate at the inlet entrance was modeled using the Real Time Control (D-RTC) module. This module controls the presence of an impermeable structure across the inlet entrance based on hydrodynamic conditions. Specifically, when the modeled water level at the U.S. Geologic Survey (USGS) gage located just outside of the gate reached $0.8 \mathrm{~m}$ NAVD, the structure was present, blocking any water from entering. This threshold was set through the analysis of historical gate closure reports and collected field data.

Operation of the facility's pumps was not included in the model. Outside of short duration tests, their operation is typically associated with extreme events as opposed to typical conditions, which are the focus of this study. Subsequent analysis demonstrates the model's ability to reproduce typical sedimentation patterns and annual quantities regardless of this simplification. Furthermore, 
any impacts due to this omission will affect each modeled scenario similarly. Because all scenarios are compared against one another, this simplification is unlikely to affect conclusions regarding the relative effectiveness of the management techniques.

In general, the model was forced at the eastern open boundary with a time series of water levels and wave information while time-varying and spatially constant winds were applied across the entire model domain. Specifics regarding these boundary conditions with respect to model calibration and application are described in the subsequent sections.

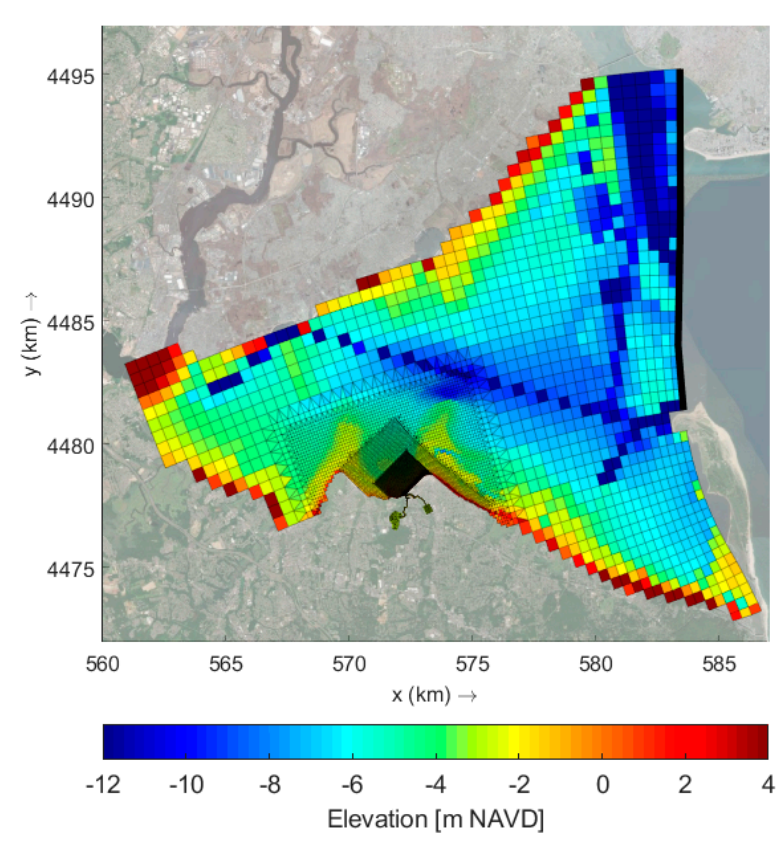

(a)

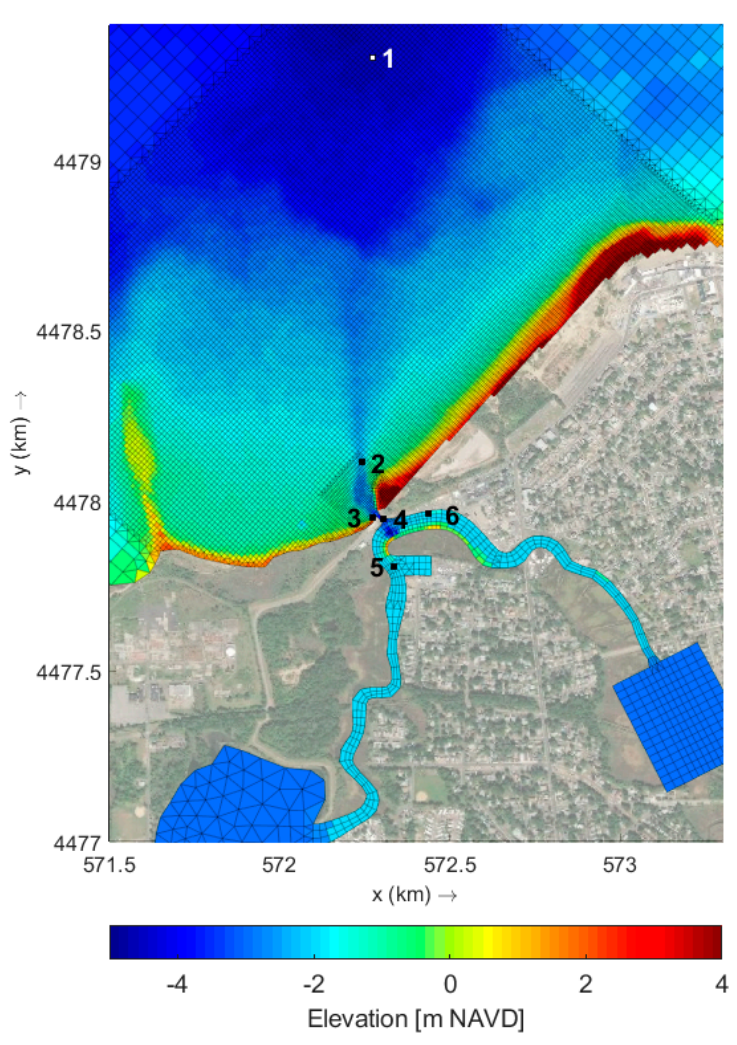

(b)

Figure 6. (a) Hydrodynamic modeling domain and grid configuration with (solid black line) eastern open boundary (b) detail in vicinity of project site. The wave modeling grid (not shown) covers the same active modeling domain and has a corresponding open boundary. Numbers denote instrument locations. See Table 3 for details.

Table 3. Sources of water levels, current profiles, and wave observations.

\begin{tabular}{ccc}
\hline ID & Name & Available Data \\
\hline 1 & Offshore & In situ wave, water level \\
2 & Ebbshoal & In situ water level, current profile \\
3 & USGS ID 01396060 & Public water level \\
4 & Inlet throat & In situ current profile \\
5 & Thornes Creek & In situ water level \\
6 & Waackaack Creek & In situ water level \\
\hline
\end{tabular}

\subsection{Development/Calibration/Evaluation}

\subsubsection{Hydrodynamics and Waves}

Calibration of the coupled hydrodynamic-wave model was completed by comparing the results, produced by running the model with specific boundary conditions with the field data collected over a 
period of one month. The chosen calibration period was from 14 April 2018 to 19 April 2018, which was the only wave event of note captured during the deployment and represents spring tides (Figure 7). The flood gate was closed during five high tides accounting for water level differences between the gages located landward and seaward of the inlet entrance. Once calibrated, the final configuration was tested for a second period, representing neap tides. A comparison of wave parameters was not possible for a validation period as the deployment did not capture a second wave event.
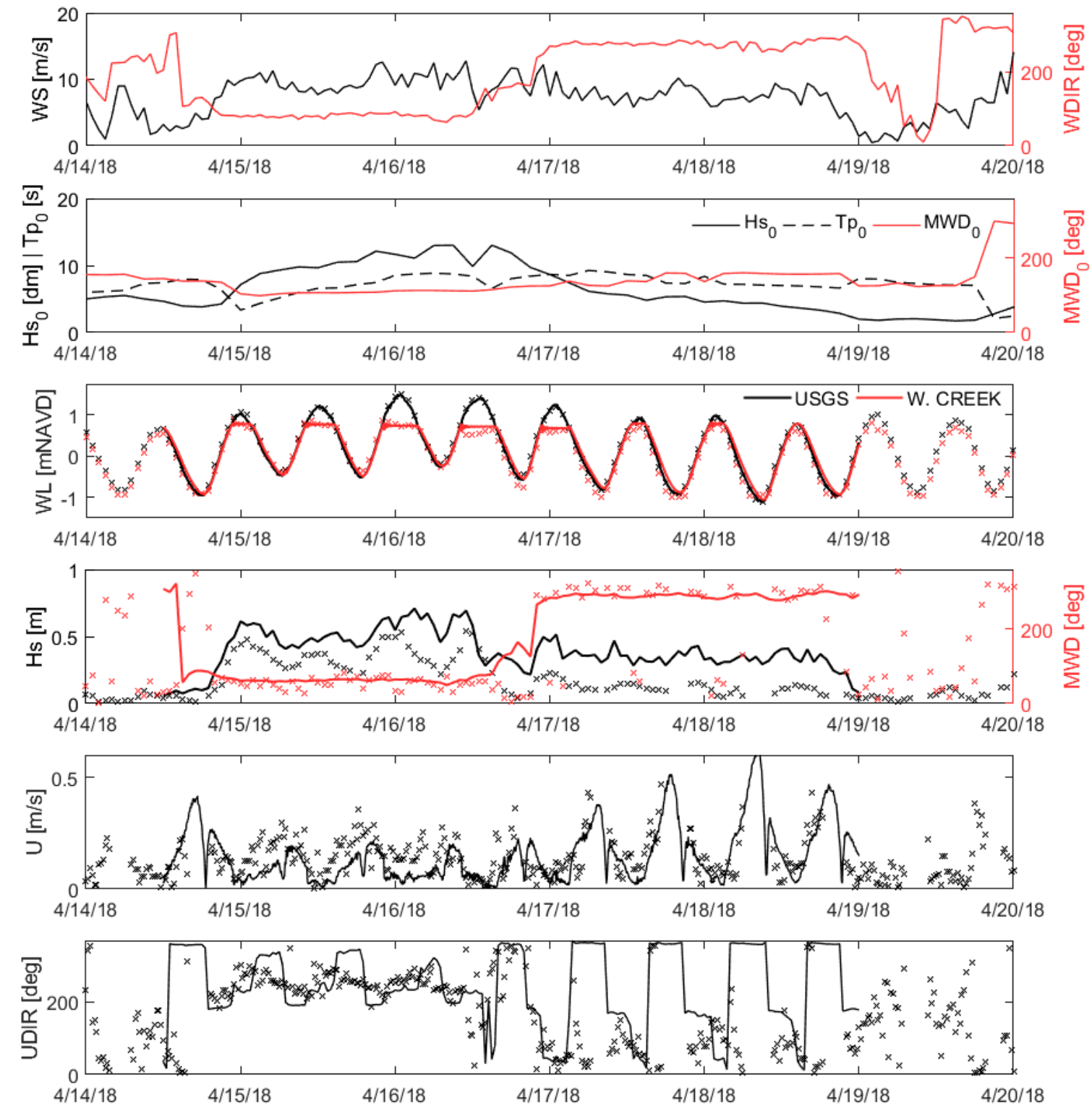

Figure 7. Collected data (X markers) for one week of the Spring 2018 deployment and modeled results (solid lines) for calibration period. TOP: Wind speed and direction as observed at Sandy Hook. SECOND: Significant wave height, period, and direction at offshore wave boundary extracted from Wavewatch III (WW3) hindcast. THIRD: Water levels at the USGS station and Waackaack Creek pressure gage. FOURTH: Significant wave height and direction at the offshore acoustic Doppler current profiler (ADCP). BOTTOM: Current speed and Direction at the Ebb Shoal Nortek ADCP.

For these two periods, the hydrodynamic model was forced at the eastern open boundary with a time series of six-minute water levels obtained from the Sandy Hook, NJ, NOAA station (ID 8531680) (top panel-Figure 7). A time series of wind speeds and directions obtained from the same station was applied across the entire model domain. Waves extracted from NOAA's Wavewatch III Hindcast 
(WW3) [51] were applied at the eastern open boundary and allowed to propagate into the bay (second panel-Figure 7). The boundary condition was applied in the form of a time series of significant wave heights, peak wave periods, and mean wave directions. Sensitivity tests later showed that the energy of these waves was typically dissipated within the bay before reaching the project site; therefore, wave forcing at the boundary was not included in the subsequent simulations used to test the sediment management alternatives.

Parameters relevant to the hydrodynamic model that were tested during calibration included the grid configuration and water level boundary conditions. Those relevant to the wave model included the bed friction and whitecapping formulations. All other parameters remained at their default values. Typically, recommended coefficients for the JONSWAP bed friction dissipation formulation $\left(0.038 \mathrm{~m}^{2} / \mathrm{s}^{3}\right.$ for swell and $0.067 \mathrm{~m}^{2} / \mathrm{s}^{3}$ for wind) were found to overestimate wave height so a larger coefficient of $0.1 \mathrm{~m}^{2} / \mathrm{s}^{3}$ was used. The Westhuysen whitecapping formulation [52] was used as it tends to lead to a better performance over the Komen (default) formulation [53] in wind-dominated seas where there is some presence of swell [54,55].

Modeled hydrodynamic (water levels, current velocities) and wave (significant wave height, mean wave direction) results were compared to data collected during the field deployment. While comparisons were made at a number of locations (Figure 6, Table 3), a representative set is presented in this paper. Goodness-of-fit statistics (Table 4) and visual comparisons (Figure 7) are provided. Statistics are provided for both the calibration and validation periods, while, for clarity, a visual comparison is only presented for the calibration period. All computed wave statistics were calculated using observations where the wave height was at least $10 \mathrm{~cm}$. This height represents the minimum height that the ADCP can measure with reasonable accuracy given the deployment specifications.

Table 4. Goodness-of-fit statistics of current velocities for model calibration and validation periods.

\begin{tabular}{cccccc}
\hline Parameter & Period & Bias & MAE $^{\mathbf{1}}$ & $\mathbf{R}$ & Lag (min) \\
\hline WL $_{\text {USGS }}(\mathrm{m})$ & Calibration & -0.04 & 0.06 & 0.99 & 10 \\
& Validation & -0.01 & 0.02 & 0.99 & 2 \\
WL $_{\text {W.CREEK }}(\mathrm{m})$ & Calibration & 0.10 & 0.13 & 0.97 & 13 \\
& Validation & 0.06 & 0.07 & 0.98 & 21 \\
$\mathrm{U}_{\mathrm{x}, \mathrm{EBBSHOAL}}(\mathrm{m} / \mathrm{s})$ & Calibration & -0.07 & 0.08 & 0.81 & - \\
& Validation & -0.04 & 0.05 & 0.17 & - \\
$\mathrm{U}_{\mathrm{y}, \mathrm{EBBSHOAL}}(\mathrm{m} / \mathrm{s})$ & Calibration & 0.04 & 0.08 & 0.62 & - \\
& Validation & 0.03 & 0.08 & 0.36 & - \\
$\mathrm{H}_{\mathrm{s}}(\mathrm{m})$ & Calibration & 0.19 & 0.19 & 0.83 & - \\
$\mathrm{MWD}(\mathrm{deg})$ & Calibration & 16 & 26 & 0.87 & - \\
\hline & \multicolumn{1}{c}{ 1 mean absolute error. } & &
\end{tabular}

Modeled water levels are reproduced well with errors generally $13 \mathrm{~cm}$ or less $(6 \%$ of the spring tidal range) and lag times 20 min or less. For the calibration period, higher errors at the Waackaack Creek gage, located landward of the inlet, are thought to be associated with flood gate operations. While the modeled gate closure occurs instantaneously once the outside water level reaches $0.8 \mathrm{~m}$ NAVD, true closure and reopening each takes approximately $12 \mathrm{~min}$ and the level at which it occurs can be subject to human judgement. However, for the purposes of this study, the operation's simplification in the model is sufficient.

When the gate remains fully open, headings shift between $0^{\circ}$ at ebb tide and $100^{\circ}$ at flood tide (bottom panel-Figure 7). This corresponds to flow moving parallel to the channel away from the inlet entrance at ebb tide to that moving approximately perpendicular to the channel at flood tide. The direction during flood tide is modeled as closer to $170^{\circ}$, corresponding to flow moving parallel to the channel towards the inlet entrance. This difference indicates that the model captures the overall behavior of the inlet (ebb/flood) and the flow magnitudes (fifth panel—Figure 7), but potentially misses some of the nuances in the flow patterns. This includes the portions of flow perpendicular to the channel, 
as observed offshore of the existing jetty. Adequate representation of flow magnitudes with skewed directions also occurs during the validation period, contributing to its poor correlation coefficients.

Periods of increased wave heights are captured, though overestimated (bias $=19 \mathrm{~cm}$ ). The relatively high R (0.83) and Figure 7 (fourth panel) highlight the model's ability to capture both increases and subsequent decreases in wave height, albeit overestimating magnitude. For the purposes of this study, where the subsequent runs used to evaluate the sedimentation management alternatives were compared against each other, this overestimation is not expected to impact the conclusions. Wave directions are modeled well, with most being within $25^{\circ}$ of the observed direction. Measured wave direction is reported as a single mean direction, but truly represents a spectrum with some directional spreading. A review of the collected spectral data indicates that the measured energy is contained within $\pm 15^{\circ}$ of the mean wave direction.

\subsubsection{Morphology}

The final model configuration described above was adopted and coupled with a morphology module to simulate bed level changes over the entirety of the deployment period. These bed level changes were compared with those measured at the end of the field deployment for model calibration. Parameters adjusted during calibration included the sediment transport formulation and those associated with the formulations designed to modify the bed and suspended transport.

The formula utilized for this study was Bijker [56]. This transport formula was selected for its robust reputation and common application in coastal areas [57]. The Bijker [56] formula models bedload and suspended load separately and includes the influence of waves. Parameters with physical meanings that could be measured directly or estimated from calculations were adjusted first, followed by unitless calibration parameters. The physical parameters included grain size, density, and settling velocity. Unitless parameters scale the current-induced suspended and bedload transport, wave transport, and parameterize shoreline erosion. A summary of the selected parameters, tested range, and default values are presented in Table 5. A single median sediment diameter $\left(\mathrm{d}_{50}\right)$ of $0.35 \mathrm{~mm}$ was used, supported by an analysis of grab samples and a review of the literature [37]. Settling velocity was estimated using both the Hallermeier [58] and Gibbs, et al. [59] formulations.

Table 5. Sediment transport module (Delft3D-SED) parameters.

\begin{tabular}{ccccccc}
\hline Parameter & Abbrev. & $\begin{array}{c}\text { Transport } \\
\text { Model }\end{array}$ & $\begin{array}{c}\text { Selected } \\
\text { Value }\end{array}$ & $\begin{array}{c}\text { Tested } \\
\text { Range }\end{array}$ & $\begin{array}{c}\text { Default } \\
\text { Value }\end{array}$ & Range \\
\hline Current related ref. concentration factor & Sus & Flow & 8 & $1-8$ & 1 & $0-$ Inf \\
Current related transport vector factor & Bed & Flow & 8 & $1-8$ & 1 & $0-$ Inf \\
Factor for erosion of adjacent dry cell & ThetSD & Flow & 0.1 & $0-0.2$ & 0 & $0-1$ \\
Median sediment diameter (mm) & D50 & Flow + Wave & 0.35 & $0.25-0.55$ & 0.2 & $>0$ \\
Settling velocity (m/s) & $\omega$ & Wave & 0.04 & $0.04-0.07$ & 0.01 & $0-$ Inf \\
Shallow water coef. & b (shallow) & Bijker (1971) & 5 & $5-6$ & 5 & $>0$ \\
Deep water coef. & b (deep) & Bijker (1971) & 2 & 2 & 2 & $>0$ \\
\hline
\end{tabular}

Due to the relatively small bed-level changes that occurred during the field deployment, and limitations of the hydrographic surveying techniques (precision and interpolation), quantitative assessment of the model performance by a skill score or RSME is inappropriate. Assessment of the model was therefore made by qualitatively comparing observed and modeled sediment transport patterns. An assessment of annualized volume errors is discussed in a later Section 5.1.

Figure 8 highlights the ability of the model to accurately recreate the sediment transport patterns observed during the Spring 2018 deployment. The replicated patterns include the refilling of the east side of the channel and erosion of the western shoal and movement of that sediment into the channel. The maximum elevation changes of $0.35 \mathrm{~m}$ throughout the area of interest are reasonable for the modeled timeframes. Accretion on the eastern beach is not reproduced due to the limitations of the $2 \mathrm{DH}$ model. Generally, Delft3D is more suitable towards modeling sedimentation patterns in 
primarily wet areas like those within the channel versus those that are intermittently wet and dry like the beach face. While a factor may be prescribed to distribute erosion of wet cells into adjacent dry ones, this is not applicable in cases of accretion.

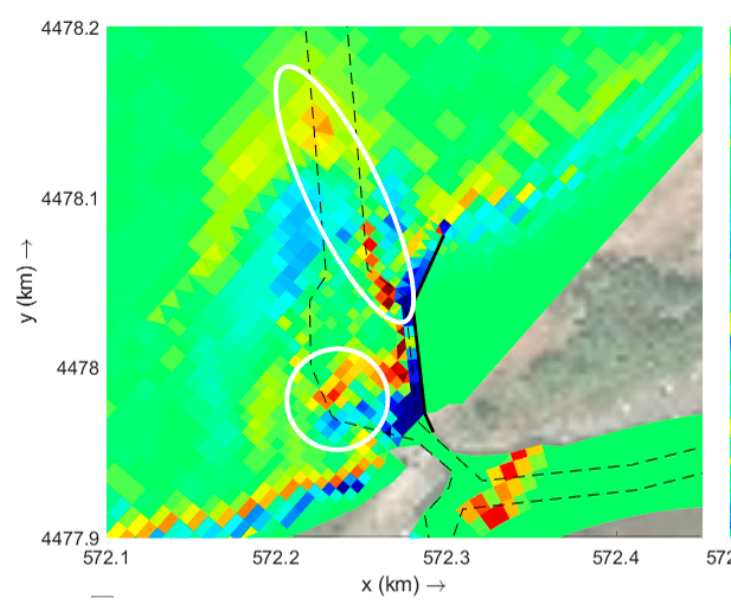

(a)

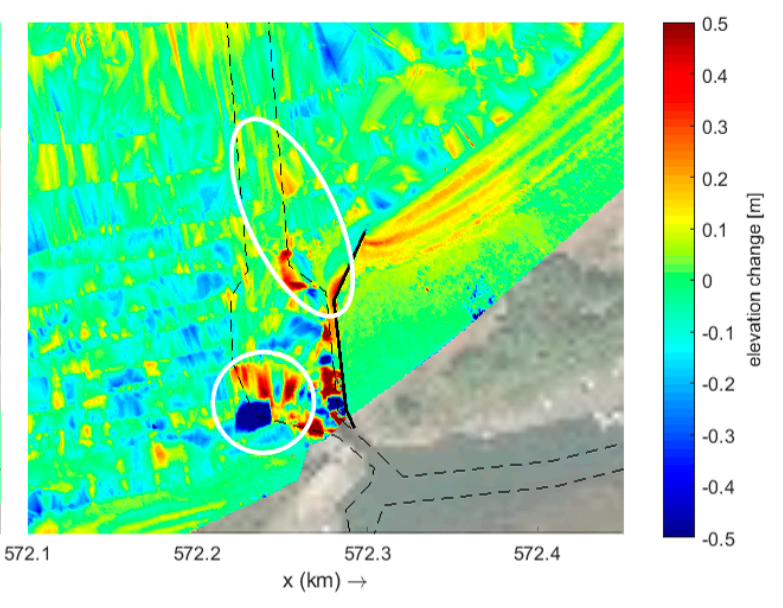

(b)

Figure 8. (a) Modeled and (b) observed cumulative erosion/sedimentation plot for the Spring 2018 deployment. Channel limits denoted by dashed line.

Scour occurring in the direct vicinity of the inlet throat is an artifact of uncharacteristically high velocities in the inlet throat. This artifact, however, is limited to the direct vicinity of the entrance as velocities dissipate quickly once outside of the throat. Within the channel limits, it results in a near-net zero volume change and does not affect conclusions drawn from subsequent testing of sediment management alternatives as it occurs in each simulation.

\subsection{Model Application}

The calibrated model was modified to assess the prospective inlet management techniques, each under a set of five representative conditions. These conditions, defined by a set of wind and water-level forcings, were selected to account for observed weather patterns. They included: Calm (i.e., Tidal only), Typical and Storm conditions associated with northwesterly (NW) and northeasterly (NE) wind sectors. These five conditions enable the quantification of the dominant sediment pathways, existing flushing capacity, and any variations due to changes in weather patterns that may influence the management strategy. The modeling of these scenarios is collectively referred to as "model application".

Each condition was modeled for one week (7 days) with a morphology change multiplication factor (MORFAC) of four. The results therefore represent the expected morphology change under the modeled conditions for four weeks (28 days). The MORFAC factor was used to reduce model run times for each scenario, facilitating the comparison of more alternatives. It is worth noting, while Delft3D can be compiled to run on Linux-based servers/supercomputers, Delft3D-FM (necessitated to adequately resolve the inlet throat) can only be compiled on a Windows operating system, limiting the computational power available to the authors. For comparison, studies by [57] have indicated simulations with MORFAC factors in excess of 1000 have remained computationally stable. The use of a MORFAC factor of four significantly reduces computational time while the scale of morphologic changes does not significantly influence the hydrodynamics. Additionally, the use of MORFAC is limited to scenarios subject to a constant wind velocity. Consequently, there are no timing impacts within the modeled scenarios.

The selected modeling approach characterizes the effectiveness of each sediment management alternative by comparing the amount of material deposited within the channel limits (i.e., dredge template) during each condition to a baseline or "do nothing" scenario. A yearly sedimentation rate 
is provided by estimating how often each scenario is likely to occur each year and extrapolating the modeled volumes. An advantage of this approach is in the ability to test the sensitivity of the yearly sedimentation volumes to the "storminess" of any given year.

Wind speeds were selected to represent the Typical and Storm conditions based on a detailed analysis of wind speeds and directions at Sandy Hook. A summary of the selected wind speeds for each condition is presented in Table 6. The Storm condition represents the average of the top $10 \%$ of wind speeds from a given direction. The Calm condition represents both winds that are: (1) less than $4 \mathrm{~m} / \mathrm{s}$ from any direction and (2) greater than $4 \mathrm{~m} / \mathrm{s}$ but from a direction without fetch. The Typical condition represents the average of those not considered as either of the two other scenarios. A combination of empirical formulas and a standalone wave model was used to confirm the use of a $4 \mathrm{~m} / \mathrm{s}$ threshold and relevant directions for Calm conditions. The use of "storm" is used for convenience and is not used in the strict definition associated with the Beaufort Scale, but rather to indicate periods of elevated wind speed and therefore elevated wave-induced sediment transport. The storm wind speeds are determined statistically, corresponding to conditions occurring less than $5 \%$ of the time irrespective of other meteorological conditions.

Table 6. Wind velocity forcing for modeled conditions.

\begin{tabular}{ccccc}
\hline Condition & Percent Occurrence & Days/Year & Wind Direction & Wind Speed (m/s) \\
\hline Calm & $47 \%$ & 172 & $\mathrm{n} / \mathrm{a}$ & $<4 \mathrm{~m} / \mathrm{s}$ \\
Calm (no waves) & $15 \%$ & 55 & SE-WSW & $>4 \mathrm{~m} / \mathrm{s}$ \\
NW sector-typical & $19 \%$ & 69 & $292.5(\mathrm{WNW})$ & $6.3 \mathrm{~m} / \mathrm{s}$ \\
NW sector-storm & $3 \%$ & 11 & $292.5(\mathrm{WNW})$ & $11.4 \mathrm{~m} / \mathrm{s}$ \\
NE sector-typical & $9 \%$ & 33 & $22.5(\mathrm{NNE})$ & $5.0 \mathrm{~m} / \mathrm{s}$ \\
NE sector-storm & $1 \%$ & 4 & $22.5(\mathrm{NNE})$ & $7.9 \mathrm{~m} / \mathrm{s}$ \\
\hline
\end{tabular}

Tidal forcing of the applied model at the open boundary was handled by creating a representative tide signal fluctuating from MLLW and MHHW to MLW and MHW. Use of a representative tide was found to have negligible impacts on the average peak flood and ebb tide speeds. Flood gate closure is not triggered by this signal. However, it is expected that during storm events, especially those where wind is coming from the northeast, or during a spring tide the gate will be intermittently closed potentially disrupting flushing processes. Intermittent closure (for several hours at high tide) was tested to determine the influence it had on morphological changes during the NE Storm and NW Storm condition. The results indicated that this type of operation had negligible impacts on sedimentation patterns and volumes. Consequently, flood gate operations were not considered in the applied model runs. Additional flood gate operations, such as extended closure during extreme surge events, were not tested as low-frequency events are outside of the scope of this study.

\subsection{Modeled Inlet Management Scenario Descriptions}

Five inlet management techniques were assessed under the defined conditions, including both structural and non-structural alternatives (Table 7, Figure 9). These included a baseline (Status Quo Dredging), two modifications to the existing jetty (including Extension or Relocation), one new structure (to the west), and a set of offshore deposition basins. For each alternative, the initial bathymetry reflected a post-dredge surface where the channel was fully dredged to the existing template. Each alternative was selected for its potential in (1) interfering with the existing sediment pathways and/or (2) modifying the channel configuration to constrain flow and improve flushing capacity. 
Table 7. Selected alternatives for modeling.

\begin{tabular}{cccc}
\hline Name & Approach & Brief Description & Objective \\
\hline Base & - & $\begin{array}{c}\text { Channel fully dredged to existing Dredge } \\
\text { Template (min. depth }-2.4 \mathrm{~m} \text { NAVD) }\end{array}$ & Do nothing/existing approach \\
\hline $\begin{array}{c}\text { Extended } \\
\text { Jetty }\end{array}$ & Structural & $\begin{array}{c}\text { Extend current jetty by } 45 \mathrm{~m} \text { along current } \\
\text { orientation for a total length of } 165 \mathrm{~m}\end{array}$ & $\begin{array}{c}\text { Assess viability of extending the } \\
\text { length of existing jetty }\end{array}$ \\
\hline $\begin{array}{c}\text { Relocated } \\
\text { Jetty }\end{array}$ & Structural & $\begin{array}{c}\text { Extend current jetty by } 45 \mathrm{~m} \text { and relocate } \\
\text { to follow initial orientation for total } \\
\text { length of } 165 \mathrm{~m}\end{array}$ & $\begin{array}{c}\text { Assess viability of narrowing the } \\
\text { inlet throat and extending the } \\
\text { length of the existing jetty }\end{array}$ \\
\hline $\begin{array}{c}\text { West Jetty } \\
\text { Addition }\end{array}$ & Structural & $\begin{array}{c}\text { Add jetty of } 75 \mathrm{~m} \text { length on western side } \\
\text { of channel }\end{array}$ & $\begin{array}{c}\text { Assess viability of modifying the } \\
\text { inlet throat and adding another } \\
\text { control structure }\end{array}$ \\
\hline $\begin{array}{c}\text { Offshore } \\
\text { Deposition } \\
\text { Basin }\end{array}$ & $\begin{array}{c}\text { Adaptive } \\
\text { Dredging } \\
\text { Technique } \\
\text { (soft solution) }\end{array}$ & $\begin{array}{c}\text { 2500 } \mathrm{m}^{2}(\text { east) to }-2.4 \mathrm{~m} \text { NAVD resulting } \\
\text { in volumes removed of } 5000 \mathrm{~m}^{3} \text { and } \\
4000 \mathrm{~m}^{3}, \text { respectively. }\end{array}$ & $\begin{array}{c}\text { Assess ability of offshore } \\
\text { deposition basins to interfere } \\
\text { with sediment bypassing }\end{array}$ \\
\hline
\end{tabular}
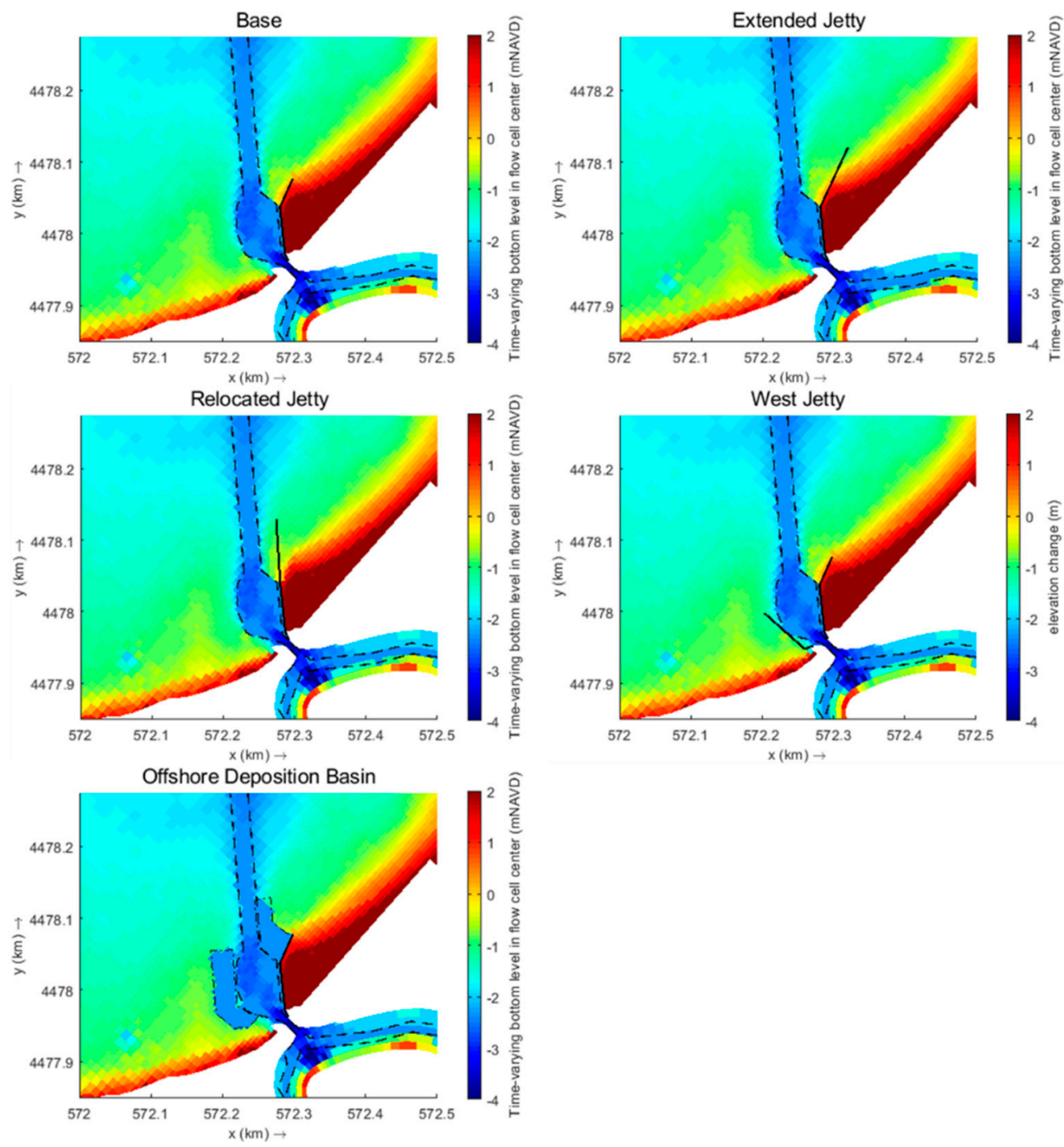

Figure 9. Modeled alternatives with initial bathymetry. Dredge template by dashed line, jetty by solid black line, and deposition basins by the dot and dashed line. 


\section{Results}

The results of the model runs are presented in the form of both visual and quantitative comparisons. First, graphic model output for a select number of conditions is presented. Figures 10 and 11 present elevation changes under WNW and NNE storm conditions occurring over 28 days. Changes during typical conditions (Supplementary Materials_-Figures S1 and S2) present similar patterns as their storm counterparts. The magnitude of changes during typical conditions however are reduced by $80-90 \%$ from storm conditions. Changes during Calm conditions (Supplementary Materials-Figure S3) are minimal. In all model runs, there is scour in the immediate vicinity of the inlet. As discussed in Section 3.2.2 (above), this is an artifact and is not expected to influence any drawn conclusions. From the baseline scenario, existing sediment pathways are identified. Design alternatives are compared to the baseline to assess how these alternatives may interfere with the pathways and reduce sedimentation within the channel limits.
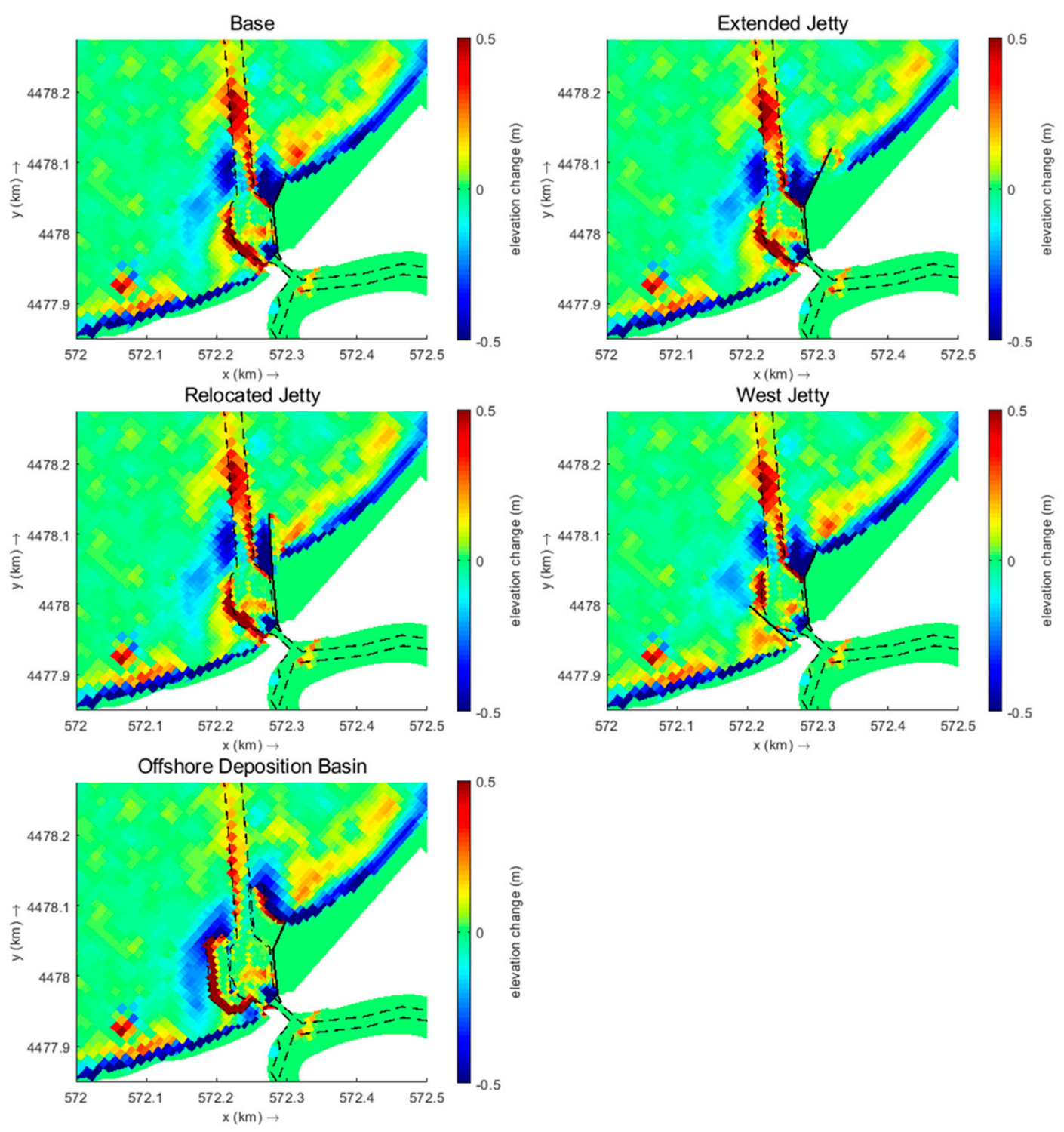

Figure 10. Cumulative sedimentation/erosion for modeled period (28 days): WNW Storm. Area of interest/channel limits by dashed line, jetty by solid black line, and deposition basins by the dot and dashed line. 

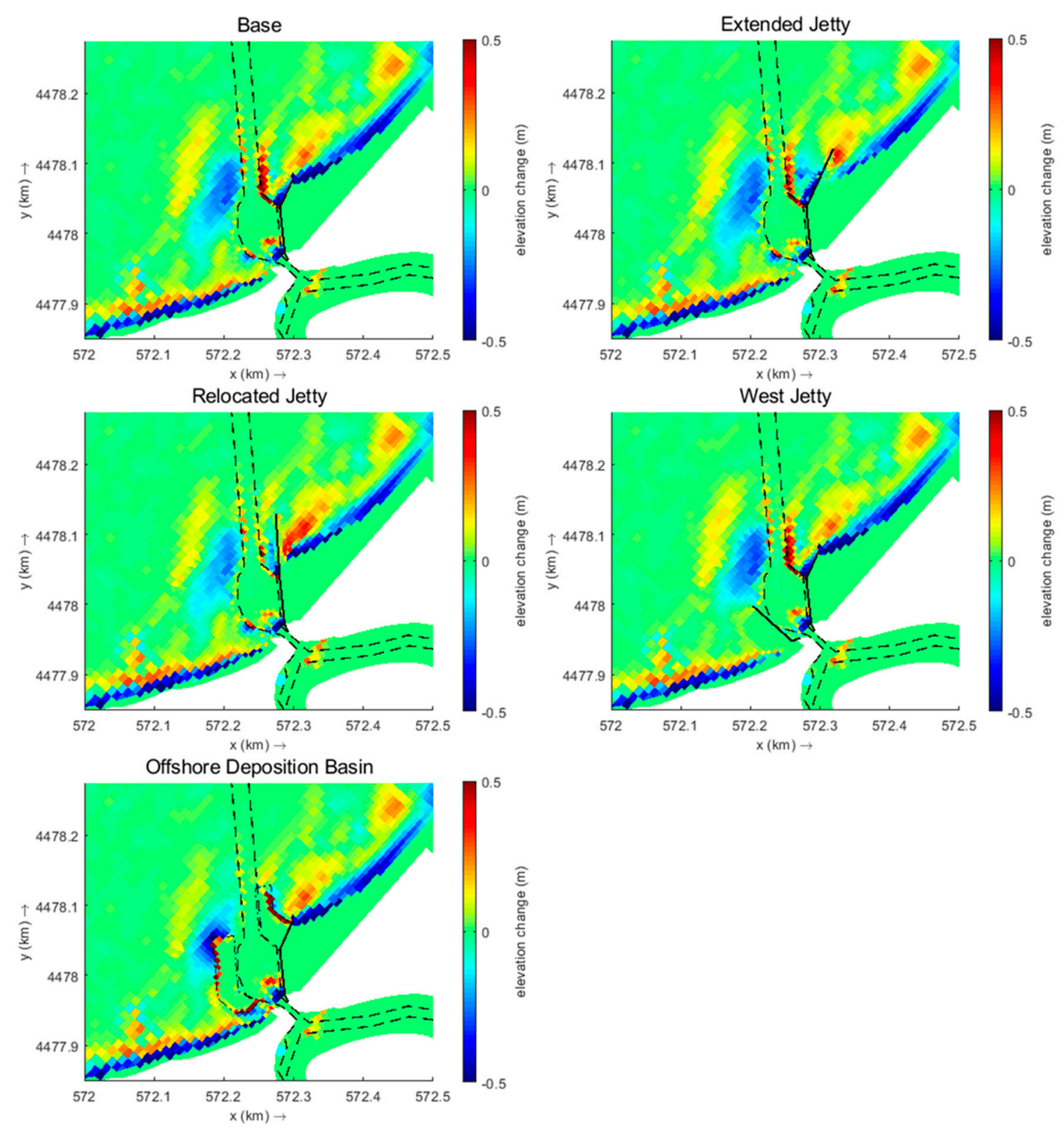

Figure 11. Cumulative sedimentation/erosion for modeled period (28 days): NNE Storm. Area of interest/channel limits by dashed line, jetty by solid black line, and deposition basins by the dot and dashed line.

In addition to these visual comparisons, volume changes within the channel limits are calculated to provide a quantitative comparison. Tables 8-10 present annual estimations of cut, fill, and net volume changes. These estimations were made by scaling the volumes calculated by the raw model results, which represent changes over 28 days. This scaling was performed by first converting these volumes to a volume rate per day and then multiplying them by the corresponding number of days for which each environmental condition occurs during a typical year (Table 6). Fill volumes (Table 8) represent that of the volume changes from all areas where sediment has accumulated. Cut volumes (Table 9) represent the sum of the volume changes from all areas where sediment has been removed within the channel limits. The net change (Table 10) is the sum of the two. Cut, fill, and net volumes are presented to not only illustrate the net volume changes, but also to capture the magnitude of total sediment transport within the channel limits. In Tables 8-10, negative values reflect sediment loss within the channel limits while positive values represent accumulation. This methodology assumes 
infilling occurs linearly in time-a non-trivial simplification. However, for the time periods and volumes in question, the simplification was deemed appropriate. A discussion of the anticipated implications is presented in Section 5.

Table 8. Annualized fill volume estimate within channel limits $\left(\mathrm{m}^{3}\right)$.

\begin{tabular}{ccccccc}
\hline Design Alternative & Tidal & NNE Storm & NNE Typical & WNW Storm & WNW Typical & Total \\
\hline Base & 1060 & 80 & 240 & 1090 & 1130 & 3600 \\
Extended Jetty & 660 & 80 & 230 & 1080 & 1110 & 3160 \\
Relocated Jetty & 630 & 60 & 220 & 1070 & 1080 & 3060 \\
West Jetty & 590 & 80 & 220 & 880 & 1030 & 2800 \\
Offshore Deposition Basin & 770 & 40 & 170 & 570 & 600 & 2150 \\
\hline
\end{tabular}

Table 9. Annualized cut volume estimate within channel limits $\left(\mathrm{m}^{3}\right)$.

\begin{tabular}{ccccccc}
\hline Design Alternative & Tidal & NNE Storm & NNE Typical & WNW Storm & WNW Typical & Total \\
\hline Base & -1200 & -30 & -170 & -140 & -440 & -1980 \\
Extended Jetty & -930 & -20 & -160 & -140 & -400 & -1650 \\
Relocated Jetty & -930 & -30 & -160 & -130 & -400 & -1650 \\
West Jetty & -880 & -20 & -160 & -120 & -400 & -1580 \\
Offshore Deposition Basin & -900 & -30 & -170 & -120 & -440 & -1660 \\
\hline
\end{tabular}

Table 10. Annualized net volume change within channel limits $\left(\mathrm{m}^{3}\right)$.

\begin{tabular}{ccccccc}
\hline Design Alternative & Tidal & NNE Storm & NNE Typical & WNW Storm & WNW Typical & Total \\
\hline Base & -150 & 60 & 80 & 950 & 700 & 1630 \\
Extended Jetty & -270 & 60 & 70 & 940 & 710 & 1520 \\
Relocated Jetty & -300 & 30 & 60 & 940 & 670 & 1400 \\
West Jetty & -300 & 60 & 70 & 760 & 630 & 1210 \\
Offshore Deposition Basin & -130 & 10 & 0 & 440 & 160 & 480 \\
\hline
\end{tabular}

In general, WNW conditions primarily result in the mobilization of sediment in the shoal just to the west of the inlet, which begins to fill in the western edge of the channel. As this continues and sediment is moved further into the channel, the inlet entrance may become choked. Some changes are observed further offshore $(\sim 250 \mathrm{~m})$. Both the West Jetty addition and Offshore Deposition Basins interfere with sediment movement during WNW conditions. While there is some bypassing with the West Jetty's tested length, infilling is reduced and is directed further from the inlet's entrance. Net volumes are reduced from the baseline scenario by $15 \%$. The Offshore Deposition Basins largely eliminates infilling of the channel nearshore while that offshore is reduced. Overall, fill volume is reduced by $60 \%$ from the baseline scenario.

NNE conditions result in the bypassing of sediment from the east around the existing jetty. Annualized volumes are approximately an order of magnitude smaller than that for WNW conditions. In the baseline scenario, infilling is shown on the eastern edge of the channel just offshore of the existing jetty. Additionally, sediment is deposited outside of the channel just offshore of the tip of the existing jetty. With more time, this sediment would potentially start to bypass the jetty as well, moving into the channel. As volume calculations do not capture this sediment, it is possible volumes associated with NNE conditions are underrepresented. The two modifications to the existing jetty (Extension and Relocation) and the Offshore Deposition Basins interfere with sediment movement during NNE conditions. While both structural modifications trap more sediment than the existing jetty, the Relocated Jetty is more effective. The eastern deposition basin appears to largely reduce infilling along the eastern edge of the channel limits. Comparisons of net volumes due to the NNE conditions show little discernible differences between the baseline scenario and the Jetty Extension. Volume changes due the relocated jetty are reduced by $35 \%$ while those for the offshore deposition basin are largely eliminated. 


\section{Discussion}

\subsection{Model and Climate Schematization}

The model results and observations suggest the sediment transport is dominated by wave action with pronounced variations in the dominant wave direction associated with distinct weather patterns. The model and climatic schematization scheme employed herein successfully capture this behavior. This is supported by the performance of the model in reproducing the sediment transport patterns observed during the Spring 2018 data collection. Application of the calibrated model to the schematized wind and wave climate agrees with the empirical observations (shoaling of the western limit of the inlet throat; bypassing and infilling around the East Jetty).

Estimated annualized volumes within the channel limits are slightly lower (9\%) than the historical observations. This difference can be explained by the omission of aeolian transport within the Delft3D model. Estimations of the annual aeolian transport indicate approximately $25 \%$ of the total sedimentation or $450 \mathrm{~m}^{3} / \mathrm{y}\left( \pm 100 \mathrm{~m}^{3} / \mathrm{y}\right)$ is due to aeolian transport over the existing jetty. Since management options for aeolian transport are addressed independently of the hydrodynamic transport, the authors elected to compare model results in the absences of direct consideration of this pathway. While total volumes should be adjusted to include this source and mitigation options, direct evaluation of the hydrodynamic modeled volumes options maintain an "apple to apples" comparison of the inlet management solutions.

It is expected that the wave-driven sedimentation for any given year may vary from the estimated rate of $1630 \mathrm{~m}^{3} / \mathrm{y}$. This is a consequence of variations in wind climate or "storminess". Years with a higher occurrence of "Calm" conditions can be expected to have reduced rates while those with more NE and NW wind events can be expected to have increased rates. Twenty years of wind velocity data (1998-2018) were analyzed to determine an expected range of 1000-2000 m³/y.

As noted earlier, the methodology employed herein assumed the sedimentation rate was constant. The morphology and hydrodynamics of the inlet are non-linear; however, a comparison of the modeled annual volume estimates and historical volumes show good agreement. It is therefore assumed the linear simplification works for the time period and volumes studied. The simplification may not perform adequately over longer periods of interest. While the volumes show good agreement, the authors hypothesize that the cumulative sedimentation/erosion plots likely contain more inherent uncertainty. As event sequencing is not considered, the magnitude of erosion and accretion in a single cell may be overly estimated. The authors expect that, while the volumes are likely correct, the elevation changes are likely to be dispersed over a greater planform area.

\subsection{Comparison of Inlet Management Solutions}

Modeled inlet management alternatives included both structural and non-structural approaches. Schematization was intended to characterize the performance of proposed solutions during typical conditions. Performance during extreme events, both from storm surge and blowout tides [60], is beyond the scope of the current work. It is acknowledged that both these events would need to be evaluated in greater detail as part of the final design, especially for the structural options.

Evaluation of the each of the sediment management alternatives has been presented with cut, fill and net volumes on an annualized basis (Tables 8-10). The comparison of "net" volume changes (Table 10) undoubtedly has the most direct and linear interpretation for dredging managers. This indicates that the Jetty Extension and Relocation options provide marginal (i.e., less than 15\%) improvements in the annualized net sedimentation volumes. Further review of the cut and fill volumes for the Jetty Extension and Relocation indicate de minims (typically less than $20 \mathrm{~m}^{3}$ ) differences from the existing (i.e., Base) conditions during the Typical and Storm conditions.

Both the Offshore Deposition Basins and the West Jetty are projected to reduce shoaling within the channel substantially, with reductions of 70 and 26\%, respectively. Direct comparisons of the annual volumes are partially misleading as the Deposition Basin is really two separate basins. This means 
the Offshore Deposition Basin is the only proposed alternative that directly addresses both dominant wind/wave directions. Consequently, it is more appropriate to compare the performance of the West Jetty and Offshore Deposition Basins for the WNW conditions or, alternatively, to include a structural solution for the East Jetty (e.g., Relocation or Extended Jetty). In the latter case, the combined effectiveness of the West Jetty and the Relocated (East) Jetty is only estimated to result in $40 \%$ reductions in annual volumes. It is worth noting that combined West Jetty and Relocated Jetty alternatives were not modeled in Delft3D simultaneously and the $40 \%$ reduction is an estimate of the cumulative impact of each approach based on modeling them independently.

For a more complete discussion, the performance of the Deposition Basins is compared herein against the West Jetty in the WNW conditions and the Relocated Jetty for the NNE conditions. As the Offshore Deposition Basins do not alter the maximum depth of the channel or the channel cross section within the inlet throat (and, by extension, will not influence the inlet's tidal prism), the performance is not anticipated to be substantially different than the Base (in situ) case under Tidal-only conditions. Modeled estimated annual differences of $20 \mathrm{~m}^{3}$ between the two cases for Tidal-only conditions support this conclusion as the difference is on the order of magnitude of rounding errors.

Shoaling in the WNW conditions is driven by two phenomena. Shoaling in the immediate vicinity of the inlet throat (proximate to the shoreline) and by offshore bar-by-passing (i.e., ebb shoal bypassing). Both patterns are identified in the Base model runs (Figure 10) and in the observed/modeled deployment of March 2018 (Figure 8). The modeled West Jetty extends $75 \mathrm{~m}$ offshore. The length, as discussed previously, is intended to be representative of something feasible from both an economic and regulatory perspective. Model results (Figure 10) clearly show that the West Jetty is successful in interfering with the nearshore longshore transport. However, the bar bypassing occurring offshore is not impacted by the jetty. While the jetty could be extended offshore to the present location of the bar, offshore depths are relatively consistent and well above the closure depth over 800-m from the shore. While sedimentation rates may be temporarily improved, once the system equilibrates, bar bypassing would be expected to rapidly return at the location of the extended West Jetty. This is attributed to the relatively shallow and consistent depths extending well offshore.

Similarly, performance of the Relocated and Extended Jetties in the NNE conditions provide temporary interference and entrapment on the updrift side. It should be noted that the existing jetty's updrift is full and has resulted in bypassing or a leaky jetty. Both provide a meager improvement; with the Relocated Jetty outperforming the Extended Jetty. The improved performance is associated to the larger projected area of the impoundment basin on the Relocated Jetty.

The model results suggest both deposition basins could provide a large enough sink as to starve the offshore bar bypassing; albeit temporarily. In essence, the structural solutions proposed work by creating entrapment basins. However, these basins are likely to be filled through natural processes and subsequently require dredging at roughly the same interval as currently. The Offshore Deposition Basins create or restore these entrapment basins without requiring the same level of capital expenditure of the structural solutions.

In theory, upland deposition basins, such as dredging the updrift portion of the existing East Jetty would work in much the same way as an offshore deposition basin, albeit with potentially lower dredging costs with terrestrial base equipment. Sensitivity runs using upland deposition basins were completed by the authors; however, limitations in the governing equations of Delft3D do not support reliable shoreline accretion modeling. Specifically, parameterization of morphology in adjacent wet/dry cells is distributed at a user-defined ratio and can only erode dry cells, but not accrete. The strength of the model lies in is its robust hydrodynamics, which are more appropriately applied to the offshore basins.

The authors acknowledge that the modeled wind speeds and waves are for typical and thus fairly benign conditions. The relationship between waves and sediment transport is non-linear. Thus, even sporadic occurrences of true storms may substantially accelerate the filling of the deposition basin. However, accelerated rates of sediment transport would apply equally to the proposed structural 
solutions as well. Consequently, while the reduction in annual volumes presented is perhaps ideal, the relative success of the deposition basins presented herein, in the authors' opinion, warrants a pilot program.

\subsection{Flood Gate Influence}

Typical operation of the flood gate has limited impacts on sedimentation patterns and volumes. This conclusion was drawn following sensitivity tests, as described in Section 3.3. These tests focused on the influence of typical operations where the gate is closed for several hours at high tide, following which it remains open until the subsequent high tide. These operations are consistent with those observed in the analyzed gate closure reports (Section 2.6).

During the time of gate closure, current velocities in the vicinity of the inlet entrance were less than $5 \mathrm{~cm} / \mathrm{s}$. Slack tide was effectively increased from approximately $15-30 \mathrm{~min}$ to $2.5 \mathrm{~h}$. Analysis of the Tidal-only scenario indicates that, under typical tidal conditions, and in the absence of flood gate closure, the inlet has limited flushing ability and sedimentation is driven by waves. Therefore, it is unlikely that any changes the flood gate has on currents will influence sedimentation volumes.

Additional operations, such as long-term closure during extreme surge events, were not tested as they are outside the scope of this study. It is acknowledged that major storms with a low occurrence rate may result in large volumes of sediment being deposited in the channel. However, as this project focused on long-term sedimentation under typical yearly conditions, these low-frequency events were not considered.

\section{Conclusions}

The results indicate that changes to the operational dredging, or what the authors have termed broadly as "adaptive dredging techniques", would likely reduce the frequency of dredging at Keansburg Inlet equal to (or better than) than traditionally applied structural solutions. The use of the Offshore Deposition Basins is the recommended management alternative and is worthy of optimization and/or pilot programs. Model results suggest that the current operational procedures of the flood gate do not significantly alter the channel infilling rates or patterns during typical (i.e., non-extreme event) conditions. Additionally:

- The Delft3D model and climate schematization captures the dominate sediment transport patterns and, when allowances are made for aeolian transport, can reproduce observed annual volume changes within $15 \%$.

- Aeolian transport over the eastern jetty is non-trivial, accounting for up to $25 \%$ of the total annual sedimentation volumes.

- The influence of the flood gate is minimal for the typical annual conditions; the authors hypothesize that it becomes more significant during extended closures with extreme weather (e.g., hurricane/nor'easter), though additional research is required.

- Non-structural solutions (i.e., offshore deposition basins) are a viable solution in lieu of traditional structural solutions for this inlet.

- The economic benefit is likely limited to reducing the frequency of dredging from 12 months to 24 months with associated cost savings limited to reducing dredge mobilization costs.

- The performance of the offshore deposition basins is likely attributed to the two opposite predominant wave directions, paired with relatively shallow depths offshore and planform locations sufficiently large enough to interfere with the longshore transport.

Supplementary Materials: The following are available online at http://www.mdpi.com/2077-1312/8/11/865/s1, Figure S1: Cumulative Sedimentation/Erosion for modeled period (28 days): WNW Typical., Figure S2: Cumulative Sedimentation/Erosion for modeled period (28 days): NNE Typical., Figure S3: Cumulative Sedimentation/Erosion for modeled period (28 days): Calm (tidal). 
Author Contributions: Conceptualization, J.K.M.; methodology, J.K.M., L.L. and M.S.J.; software, L.L. and M.S.J.; formal analysis, L.L. and M.S.J.; data curation, M.S.J.; writing-original draft preparation, L.L. and M.S.J.; writing-review and editing, J.K.M.; visualization, L.L. and M.S.J.; supervision, J.K.M.; project administration, J.K.M.; funding acquisition, J.K.M. All authors have read and agreed to the published version of the manuscript.

Funding: This research was funded by W. Scott Douglas of the Office Maritime Resources, New Jersey Department of Transportation, grant number 17-32666.

Acknowledgments: The authors gratefully acknowledge the faculty, staff, and students of the Coastal Engineering Research Group at Davidson Laboratory, Stevens Institute of Technology, who contributed to field data collection, thus enabling the calibration and evaluation of the numerical model. The authors also acknowledge C.M. (Kees) Nederhoff of Deltares USA for the valuable technical assistance and guidance regarding Delft3D-FM.

Conflicts of Interest: The authors declare no conflict of interest. The funders had no role in the design of the study; in the collection, analyses, or interpretation of data; in the writing of the manuscript, or in the decision to publish the results.

\section{References}

1. Tooley, M.J.; Ehlers, J. The Morphodynamics of the Wadden Sea. Geogr. J. 1990, 156, 81. [CrossRef]

2. Hayes, M.O. The Georgia Bight Barrier System. In Geology of Holocene Barrier Island Systems; Springer Science and Business Media LLC: Berlin/Heidelberg, Germany, 1994; pp. 233-304.

3. Davis, R.A.; Hayes, M.O. What is a wave-dominated coast? Mar. Geol. 1984, 60, 313-329. [CrossRef]

4. Escoffier, F.F. Hydraulics and Stability of Tidal Inlets; USACE: Fort Belvoir, VA, USA, 1977; p. 74.

5. Escoffier, F.F. The stability of tidal inlets. Shore Beach 1940, 8, 3.

6. Ranasinghe, R.; Pattiaratchi, C. The Seasonal Closure of Tidal Inlets: Causes and Effects. Coast. Eng. J. 2003, 45, 601-627. [CrossRef]

7. Oertel, G.F. Sediment Transport of Estuary Entrance Shoals and the Formation of Swash Platforms. J. Sediment. Res. 1972, 42, 858-863. [CrossRef]

8. Jarrett, J.T. Tidal Prism-Inlet Relationships; US Army Corps of Engineers: Vicksburg, MS, USA, 1976.

9. O'Brien, M.P. Equilibrium flow areas of inlets on sandy coasts. J. Waterw. Port Coast. Ocean Eng. 1969, 95, 9.

10. Bruun, P.; Gerritsen, F. STABILITY OF COASTAL INLETS. In Proceedings of the Coastal Engineering; Coastal Engineering Research Council: The Hague, The Netherlands, 1960; Volume 1, pp. 386-417.

11. Keulegan, G.H. Tidal Flow in Entrances; Technical Bulletin 14; U.S. Army Corps of Engineers: Vicksburg, MS, USA, 1967.

12. Elias, E.P.; Hansen, J.E. Understanding processes controlling sediment transports at the mouth of a highly energetic inlet system (San Francisco Bay, CA). Mar. Geol. 2013, 345, 207-220. [CrossRef]

13. Reyes-Merlo, M.Á.; Ortega-Sánchez, M.; Díez-Minguito, M.; Losada, M.A. Efficient dredging strategy in a tidal inlet based on an energetic approach. Ocean. Coast. Manag. 2017, 146, 157-169. [CrossRef]

14. Petti, M.; Bosa, S.; Pascolo, S.; Uliana, E. An Integrated Approach to Study the Morphodynamics of the Lignano Tidal Inlet. J. Mar. Sci. Eng. 2020, 8, 77. [CrossRef]

15. Zarzuelo, C.; López-Ruiz, A.; Ortega-Sánchez, M. Evaluating the impact of dredging strategies at tidal inlets: Performance assessment. Sci. Total. Environ. 2019, 658, 1069-1084. [CrossRef]

16. Fernández-Fernández, S.; Ferreira, C.; Silva, P.A.; Baptista, P.; Romão, S.; Fontán-Bouzas, Á.; Abreu, T.; Bertin, X. Assessment of Dredging Scenarios for a Tidal Inlet in a High-Energy Coast. J. Mar. Sci. Eng. 2019, 7, 395. [CrossRef]

17. Shaeri, S.; Tomlinson, R.; Etemad-Shahidi, A.; Strauss, D. Numerical modelling to assess maintenance strategy management options for a small tidal inlet. Estuar. Coast. Shelf Sci. 2017, 187, 273-292. [CrossRef]

18. Olsen Associates Inc. Calibration of A Delft3D Model for Bald Head Island and the Cape Fear River Entrance Phase 1; Olsen Associates Inc.: Jacksonville, FL, USA, 2012.

19. Mendes, D.; Fortunato, A.B.; Pires-Silva, A.A. Assessment of three dredging plans for a wave-dominated inlet. Proc. Inst. Civ. Eng. Marit. Eng. 2016, 169, 64-75. [CrossRef]

20. Behrens, D.K.; Bombardelli, F.A.; Largier, J.L.; Twohy, E. Episodic closure of the tidal inlet at the mouth of the Russian River-A small bar-built estuary in California. Geomorphology 2013, 189, 66-80. [CrossRef]

21. Bertin, X.; Fortunato, A.B.; Oliveira, A. A modeling-based analysis of processes driving wave-dominated inlets. Cont. Shelf Res. 2009, 29, 819-834. [CrossRef] 
22. Castelle, B.; Bourget, J.; Molnar, N.; Strauss, D.; Deschamps, S.; Tomlinson, R. Dynamics of a wave-dominated tidal inlet and influence on adjacent beaches, Currumbin Creek, Gold Coast, Australia. Coast. Eng. 2007, 54, 77-90. [CrossRef]

23. Bruun, P. Morphological and Navigational Aspects of Tidal Inlets on Littoral Drift Shores. J. Coast. Res. 1986, 2, 123-145.

24. Herrington, T.O. An Analysis of The Sedimentation Problem at Monmouth Cove Marina, Monmouth County, New Jersey; TR SIT-DL-9-2683; Stevens Institute of Technology, Davidson Laboratory: Hoboken, NJ, USA, 1994; p. 117.

25. O'Brien, M.P. Estuary and tidal prisms related to entrance areas. Civ. Eng. 1931, 1, 2.

26. Bruun, P.; Gerritsen, F. Stability of Coastal Inlets; North-Holland Pub. Co.: Amsterdam, The Netherlands, 1966.

27. Eelkema, M.; Wang, Z.B.; Hibma, A.; Stive, M. Morphological Effects of the Eastern Scheldt Storm Surge Barrier on the Ebb-Tidal Delta. Coast. Eng. J. 2013, 55, 1350010. [CrossRef]

28. Du, J.; Shen, J.; Bilkovic, D.M.; Hershner, C.H.; Sisson, M. A Numerical Modeling Approach to Predict the Effect of a Storm Surge Barrier on Hydrodynamics and Long-Term Transport Processes in a Partially Mixed Estuary. Chesap. Sci. 2016, 40, 387-403. [CrossRef]

29. Kriebel, D.L.; Henderson, G.R. ASSESSING CURRENT AND FUTURE NUISANCE FLOOD FREQUENCY THROUGHOUT THE U.S. MID-ATLANTIC. Coast. Eng. Proc. 2018, 1, 106. [CrossRef]

30. Moftakhari, H.R.; AghaKouchak, A.; Sanders, B.F.; Matthew, R.A. Cumulative hazard: The case study of nuisance flooding. Earth's Future 2017, 5, 214-223. [CrossRef]

31. NJDEP. Bayshore Floodgate Facility. Available online: https://www.nj.gov/dep/shoreprotection/bayshore.htm (accessed on 3 December 2019).

32. Davies, J. A morphogenic approach to world shorelines. Zeitschrift für Geomorphol. 1964, 8, 127-142. [CrossRef]

33. Coastal Engineering Research Center. Shore Protection Manual; Waterways Experiment Station, Corps of Engineers: Vicksburg, MS, USA, 1984.

34. USACE. Application of Adult and Juvenile Winter Flounder Data to Habitat Uses In New York/New Jersey Harbor; USACE: Washington, DC, USA, 2012; p. 79.

35. Bokuneiwicz, H. A Brief Summary of the Geology of Raritan Bay; NOAA Estuary-of-the-Month 1988, Seminar Series No. 9, 45-57; NOAA: Washington, DC, USA, 1988.

36. ESS Group. Modeling of Sediment Dispersion during Installation of the Submarine Cable for the Poseidon Project 2013; ESS Group: Los Angeles, CA, USA, 2013; p. 59.

37. Flynn, M.J. Sediment Characterization of The New Jersey Shoreline: Comparison of Median Grain Size Distribution From 1950 To 2011; The Richard Stockton College Coastal Research Center: Port Republic, NJ, USA, 2013.

38. Gahagan \& Bryant Associates, Inc. Maintenance Dredging and Channel Improvements for Waackaack Creek-Contract No. 005201703; State of New Jersey NJDOT Office of Maritime Resources: Trenton, NJ, USA, 2017.

39. Bayshore Regional Watershed Council; NJDOT; OMR. Northern Bayshore Dredged Material Management Plan "Identifying Beneficial Uses for Dredged Material" Raritan and Sandy Hook Bays Monmouth County, New Jersey; NJDOT: Trenton, NJ, USA, 2009; p. 74.

40. Hsu, S.A. Boundary-Layer Meteorological Research in the Coastal Zone; School of Geoscience, Louisiana State University: Baton Rouge, LA, USA, 1977.

41. Hsu, S.A. Correction of Land-Based Wind Data for Offshore Applications: A Further Evaluation. J. Phys. Oceanogr. 1986, 16, 390-394. [CrossRef]

42. USACE. Coastal Engineering Manual; USACE: Washington, DC, USA, 2011.

43. USACE. Raritan Bay and Sandy Hook Bay Highlands, New Jersey Coastal Rish Management Feasibility Study: Final Integrated Feasibility Report and Environmental Assessment; USACE: Washington, DC, USA, 2020; p. 127.

44. USACE. Keansburg, East Keansburg, and Lawrence Harbor, New Jersey: Draft Reevaluation Report Beach Fill Renourishment; USACE: Washington, DC, USA, 2007; p. 66.

45. Lesser, G.; Roelvink, J.; Van Kester, J.; Stelling, G. Development and validation of a three-dimensional morphological model. Coast. Eng. 2004, 51, 883-915. [CrossRef]

46. Booij, N.; Ris, R.C.; Holthuijsen, L. A third-generation wave model for coastal regions: 1. Model description and validation. J. Geophys. Res. Space Phys. 1999, 104, 7649-7666. [CrossRef] 
47. Ris, R.C.; Holthuijsen, L.; Booij, N. A third-generation wave model for coastal regions: 2. Verification. J. Geophys. Res. Space Phys. 1999, 104, 7667-7681. [CrossRef]

48. Miller, J.; Mahon, A.; Herrington, T. Development of the Stevens Dynamic Underwater Coastal Surveying (DUCKS) System; Davidson Laboratory Technical Report; Coastal Protection Techanical Assistance Service: Hoboken, NJ, USA, 2009.

49. Zimmerman, T.; Jansen, K.; Miller, J. Analysis of UAS Flight Altitude and Ground Control Point Parameters on DEM Accuracy along a Complex, Developed Coastline. Remote Sens. 2020, 12, 2305. [CrossRef]

50. Cooperative Institute for Research in Environmental Sciences. Continuously Updated Digital Elevation Model (CUDEM)—1/9 Arc-Second Resolution Bathymetric-Topographic Tiles. [Northeast-Sandy]; NOAA National Centers for Environmental Information: Boulder, CO, USA, 2014.

51. NOAA/NCEP/EMC. WAVEWATCH III Production Hindcast, Multigrid. Available online: https://polar.ncep. noaa.gov/waves/hindcasts/prod-multi_1.php (accessed on 3 December 2019).

52. Van der Westhuysen, A.J. Advances in the Spectral Modelling of Wind Waves in The Nearshore. Ph.D. Thesis, Delft University of Technology, Delft, The Netherlands, 2007.

53. Komen, G.J.; Hasselmann, K. On the Existence of a Fully Developed Wind-Sea Spectrum. J. Phys. Oceanogr. 1984, 14, 1271-1285. [CrossRef]

54. Mulligan, R.P.; Bowen, A.J.; Hay, A.E.; Van Der Westhuysen, A.J.; Battjes, J.A. Whitecapping and wave field evolution in a coastal bay. J. Geophys. Res. Space Phys. 2008, 113, 1-16. [CrossRef]

55. Moeini, M.H.; Etemad-Shahidi, A. Wave Parameter Hindcasting in a Lake Using the SWAN Model. Sci. Iran Trans. A 2009, 16, 156-164.

56. Bijker, E.W. Littoral Drift Computations on Mutual Wave and Current Influence; Delft University of Technology: Delft, The Netherlands, 1971.

57. Deltares. D-Morphology, 1D/2D/3D, User Manual; Deltares: Delft, The Netherlands, 2020; p. 138.

58. Hallermeier, R.J. Terminal settling velocity of commonly occurring sand grains. Sedimentology 1981, 28, 859-865. [CrossRef]

59. Gibbs, M.D.M.R.J. The Relationship Between Sphere Size and Settling Velocity. J. Sediment. Res. 1971, 41, 7-18. [CrossRef]

60. Gurumurthy, P.; Orton, P.M.; Talke, S.A.; Georgas, N.; Booth, J.F. Mechanics and Historical Evolution of Sea Level Blowouts in New York Harbor. J. Mar. Sci. Eng. 2019, 7, 160. [CrossRef]

Publisher's Note: MDPI stays neutral with regard to jurisdictional claims in published maps and institutional affiliations.

(C) 2020 by the authors. Licensee MDPI, Basel, Switzerland. This article is an open access article distributed under the terms and conditions of the Creative Commons Attribution (CC BY) license (http://creativecommons.org/licenses/by/4.0/). 